\title{
The spo0A-sinl-sinR Regulatory Circuit Plays an Essential Role in Biofilm Formation, Nematicidal Activities, and Plant Protection in Bacillus cereus AR156
}

\author{
Sunde Xu, ${ }^{1}$ Nan Yang, ${ }^{1}$ Shiyu Zheng, ${ }^{1}$ Fang Yan, ${ }^{2,3}$ Chunhao Jiang, ${ }^{3}$ Yiyang $Y u,{ }^{2,3}$ Jianhua Guo, ${ }^{3}$ \\ Yunrong Chai, ${ }^{2}$ and Yun Chen ${ }^{1}$ \\ ${ }^{1}$ Institute of Biotechnology, Zhejiang University, Hangzhou 310058, China; ${ }^{2}$ Department of Biology, Northeastern University, \\ Boston 02115, U.S.A.; and ${ }^{3}$ Department of Plant Pathology, Nanjing Agricultural University, Nanjing 210095, China
}

Accepted 19 April 2017.

\begin{abstract}
The rhizosphere bacterium Bacillus cereus AR156 is capable of forming biofilms, killing nematodes, and protecting plants. However, the underlying molecular mechanisms of these processes are not well understood. In this study, we found that the isogenic mutants $\triangle B$ cspoOA and $\triangle B c$ sinI have significantly reduced colonization and nematicidal activity in vitro and biological control efficacy on the tomato plant under greenhouse conditions. We further investigated the role of the $\operatorname{spo} 0 A-\sin I-\sin R$ regulatory circuit in biofilm formation, killing against nematodes, and biological control in AR156. Results from mutagenesis of those regulatory genes in AR156 and their heterologous expression in $B$. subtilis suggested that the $\operatorname{spo} 0 A-\sin I-\sin R$ genetic circuit is not only essential for biofilm formation and cell differentiation in AR156 but also able to functionally replace their counterparts in B. subtilis in a nearly indistinguishable fashion. Genome-wide transcriptional profiling in the wild type and the $\triangle B$ cspoOA and $\Delta B c$ inI mutants further revealed hundreds of differentially expressed genes, likely positively regulated by both Spo0A and SinI (via SinR) in AR156. Among them, 29 genes are predicted to be directly controlled by SinR, whose counterpart in B. subtilis is a biofilm master repressor. Collectively, our studies demonstrated the essential role of the spo0A-sinI-sinR regulatory circuit in biofilm formation, cell differentiation, and bacteria-host interactions in B. cereus AR156.
\end{abstract}

Southern root-knot nematode (Meloidogyne incognita), an obligate, sedentary endoparasite, is one of the most economically important plant-parasitic nematodes of horticultural crops (Hunt and Handoo 2009). It can infect the roots of more than 3,000 different horticultural crops and subsequently form giant cells, causing huge yield loss worldwide (Jones et al. 2013; Sikora and Fernandez 2005). Due to the increase of greenhousegrown crops and multiple cropping (growing two or more crops consecutively or at the same time on the same field in the same year), this nematode results in considerable average annual vegetable yield losses of 20 to $30 \%$ in China (Shi et al. 2010). $M$. incognita is difficult to control, in part due to its short generation

Corresponding authors: Y. Chen; Telephone: $(+86) 57188982106$; Fax (+86) 571 88982268; E-mail: chenyun0927@zju.edu.cn; Y. Chai, E-mail: y.chai@northeastern.edu; and J. Guo, E-mail: jhguo@njau.edu.cn

*The $\boldsymbol{e}$-Xtra logo stands for "electronic extra" and indicates that six supplementary figures and six supplementary tables are published online.

@ 2017 The American Phytopathological Society time and a high reproductive rate (Manzanilla-López et al. 2004; Trudgill and Blok 2001). For decades, control of $M$. incognita has heavily relied on the use of chemical nematicides, especially the fumigate nematicides. However, use of some chemical nematicides has been restricted or withdrawn because of their potential negative effects on the environment, nontarget organisms, and human health (Giannakou et al. 2002; Huang et al. 2014; Zasada et al. 2010). Therefore, there is an urgent need for finding novel, environmentally friendly, and more effective alternative solutions. Biological control has shown promise as an ecologically friendly approach for controlling $M$. incognita. Several biological control agents (BCA) and their secondary metabolites with killing activities against $M$. incognita have been developed for the control of root-knot nematode diseases (Kerry 2000). To date, more than 700 species of nematophagous fungi have shown potential nematicidal activities, including Ascomycota, Basidiomycota, Chytridiomycota, and Zygomycota spp. (Li et al. 2015). Among them, Myrothecium verrucaria, Paecilomyces lilacinus, Pochoniachlamy dosporium, and Trichoderma spp. have been commercialized for biological control of rootknot nematodes. In addition to nematophagous fungi, bacterial BCA are also important microorganisms able to reduce the rootknot nematode diseases. Based on their mode of action, bacterial BCA against nematodes can be classified into the following groups: obligate parasitic bacteria, opportunistic parasitic bacteria, rhizobacteria, parasporal Cry protein-forming bacteria, endophytic bacteria, and symbiotic bacteria (Tian et al. 2007). Bacteria belonging to the genera Bacillus, Pseudomonas, and Pasteuria represent the dominant populations of nematophagous bacteria in the soil (Ali et al. 2002; Nielsen-LeRoux et al. 2012; Niu et al. 2010; Preston et al. 2003; Tan et al. 1999).

Biofilms are microbial multicellular communities in which individual cells are held together by a self-produced extracellular matrix (O'Toole et al. 2000). It has been widely recognized that most microbes can colonize abiotic and biotic surfaces in the formation of biofilms in natural, clinical, and industrial settings (Davey and O'Toole 2000). In the last decade, the structure and regulation of the bacterial biofilms have been extensively investigated in model microorganisms such as Pseudomonas aeruginosa, Escherichia coli, Staphylococcus aureus, and Bacillus subtilis (Branda et al. 2005; Lemon et al. 2008). In B. subtilis, the biofilm matrix consists of the hydrophobin protein BslA, exopolysaccharides (EPS), and protein fibers TasA, encoded by the $b s l A$ gene and the epsA-O and tapA-sipW-tasA operons, respectively (Fig. 1A) (Branda et al. 2001, 2006; Chu et al. 2006; Hobley et al. 2015; Romero et al. 2010). In B. subtilis, biofilm formation can be triggered by 
multiple histidine kinases sensing environmental and physiological signals, leading to protein phosphorylation and activation of the master regulator Spo0A, via a phosphor-relay (Grossman 1991; Jiang et al. 2000; McLoon et al. 2011). Spo0A activates biofilm formation by increasing production of SinI, a small protein antagonist of the biofilm master repressor SinR (Bai et al. 1993). SinR directly represses two matrix component operons, epsA-O and tapA-sipW-tasA (Branda et al. 2006; Chai et al. 2011; Newman et al. 2013). The gene for BslA was shown to be directly or indirectly regulated by the response regulator DegU and the transcription repressors SinR and AbrB (Verhamme et al. 2009). Two additional small antagonists of SinR, SlrA and SlrR, also play a role in the regulation of biofilm formation by interacting with SinR (Chai et al. 2009, 2010). Evidence indicates that $\operatorname{SinR}$ and SlrR constitute a selfreinforcing double-negative loop that locks a population of cells in the matrix-producing state (Fig. 1A) (Chai et al. 2010). SlrA has been shown to directly interact with SinR and relieve SinR-mediated repression of matrix genes (Fig. 1A) (Chai et al.
2009; Newman and Lewis 2013). Like B. subtilis, various $B$. cereus strains have been reported to form biofilms under either laboratory or environmental conditions (Gao et al. 2015; Ryu and Beuchat 2005; Shemesh and Chai 2013; Wijman et al. 2007). However, in contrast to $B$. subtilis, few genes involved in biofilm formation have been characterized in B. cereus and the regulatory mechanisms that control biofilm formation in that bacterium are poorly understood.

Rhizosphere bacteria are frequently found to form microcolonies or biofilm-like structures on plant roots (Morris and Monier 2003). Studies have demonstrated that biofilm formation by BCA plays an important role in plant protection and disease control. For instance, mucoid mutants of the biocontrol strain P. fluorescens CHA0 showed more robust biofilm formation and increased colonization on carrot roots, which correlated with decreased plant infection (Bianciotto et al. 2001). Paenibacillus polymyxa was shown to colonize peanut root tips, forming biofilm-like structures and suppressing the crown rot disease caused by Aspergillus niger (Haggag and Timmusk 2008;

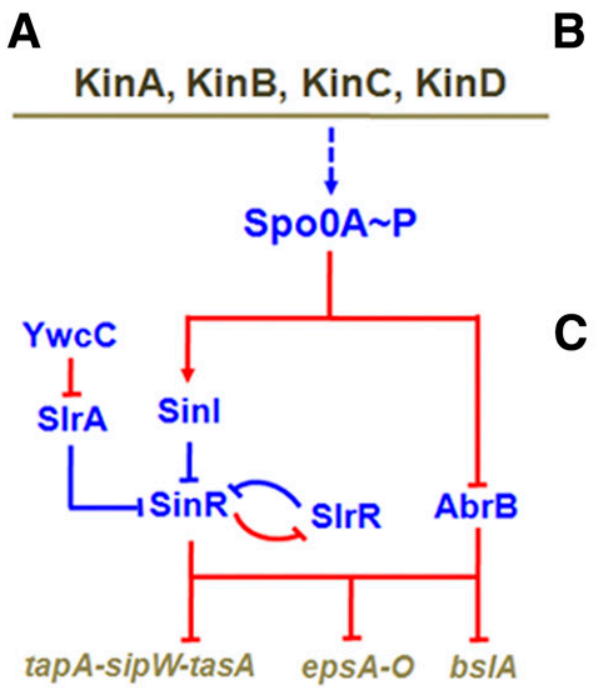

B. cereus AR156

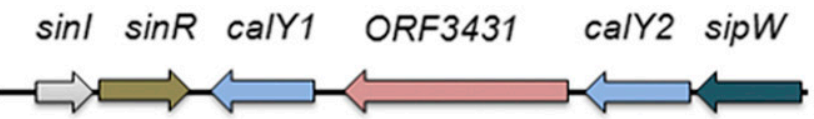

B. subtilis 168

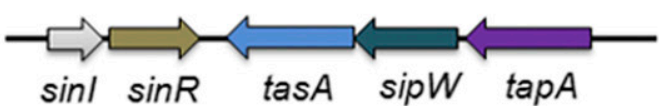

C


BaSinl:--MYKDKT DALDQEWIDLILEALDAGIALQDIEHFFKRMK------PSSQAQ----- : 44 BsSinl:MKNAKQEHFELDQEWVELMVEAKEANISPEEIRKYLLLNKKSAHPGPAARSHTVNPF : 57

BcsinR: LIERCANMIGERIKRLRLQKGI SLTELAEKAGVAKSYISS IERNLQKNPSIQFLEKIAA :59 BaSinR:-------MIGERIKRLRLQKGISLTELAEKAGVAKSYISSIERNLQKNPSIQFLEKIAA :52 BSSinR:-------MIGQRIKQYRKEKGYSLSELAEKAGVAKSYLSSIERNLQTNPSIQFLEKVSA : 52

$$
\text { DNA binding domain }
$$

VLQIPPV̄DTLLHDETTKĒNH--LDSEWT QLVKDAMNSGVSKEQFREFLEFTTKWKQDQK-- : 114 VLQIPVDTLLHDETTKEAN--LDSEWTQLIKDAMNSGVSKEQFREFLEFTKWKQNQK-- : :107 VLDVSVHTLLDEKHETEYDGQLDSEWEKLVRDAMTSGVSKKQFREFLDYQKWRKSQKEE :111

SinI-SinR interaction domain

D

\begin{tabular}{|c|c|c|c|}
\hline \multirow{3}{*}{ BsSinI } & & 10 & \multirow{2}{*}{8} \\
\hline & M-- & - LDQEWVELMVEAKEANISPEEIRKYLLLNKKSAHPGPA & \\
\hline & & 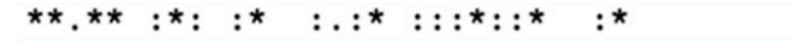 & \\
\hline \multirow[t]{3}{*}{ BsSinR } & M--- & LDSEWEKLVRDAMTSGVSKKQFREFLDYQKWRKSQKEE & 111 aa \\
\hline & & 111 & \\
\hline & & 44 & \\
\hline \multirow[t]{2}{*}{ BCSinI } & M--- & LDQEWIDLILEALDAGIAMQDIEQFFQRMKPSSQAQ & 44 aa \\
\hline & & 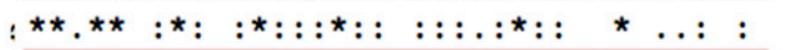 & \\
\hline \multirow[t]{2}{*}{ BcsinR } & $\mathrm{L}--$ & LDSEWTQLVKDAMNSGVSKEQFREFLEFTKWKQDQK & 114 aa \\
\hline & & 114 & \\
\hline
\end{tabular}

Fig. 1. Putative regulatory circuit for biofilm formation in Bacillus cereus AR156. A, Schematic presentation of the regulatory circuit for the control of biofilm formation in B. subtilis. Spo0A is at the center of the regulatory circuit, controlling genes involved in biofilm formation. Multiple histidine kinases directly or indirectly activate Spo0A through phosphorylation. SinR and AbrB are two master repressors of the biofilm matrix genes tapA-sipW-tasA, espA-O, and bslA. SinR is antagonized by two parallel antirepressors (SinI and SlrA). SlrR is another counteracting protein of SinR. These two proteins constitute a selfreinforcing double-negative loop for the control of matrix genes. YwcC is another biofilm repressor and negatively regulates the $s l r A$ gene. Gene regulation is

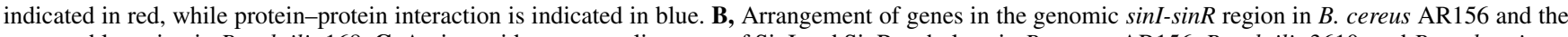
comparable region in B. subtilis 168. C, Amino acid sequence alignment of SinI and SinR orthologs in B. cereus AR156, B. subtilis 3610, and B. anthracis str. Ames. The DNA-binding domain and the domain interacting with SinI are underlined in blue and red, respectively. D, Sequence alignment of the two-helical hook regions of SinR and SinI orthologs in both B. subtilis and B. cereus. Key residues involved in the interaction between BsSinI and BsSinR, as revealed in the cocrystal structure, are highlighted in red. Corresponding residues are also indicated in the BcSinI-BcSinR alignment, with the differentiation residues indicated in green. Alignments were created using ClustalW. 
Timmusk et al. 2005). B. subtilis strain ATCC 6051 was able to form biofilm-like structures on the roots of Arabidopsis plants and protect Arabidopsis from infections by Pseudomonas syringae (Bais et al. 2004). In our previous study (Chen et al. 2012), we demonstrated that B. subtilis BCA could sense plantreleased small signal molecule ${ }_{L}$-malic acid via a histidine kinase receptor $\mathrm{KinD}$, and subsequently trigger formation of plant-root-associated biofilms. We also showed that the biofilm-forming ability of various $B$. subtilis BCA correlated with their biocontrol efficacy against tomato Ralstonia wilt disease (Chen et al. 2013). In another study, a B. subtilis UMAF6614 strain produced surfactin to trigger biofilm formation on melon phylloplane, which ensured long-term persistence and adequate secretion of suppressive lipopeptides against plant pathogens (Zeriouh et al. 2014). Although increasing evidence has suggested that beneficial biofilms by BCA are important for biocontrol activities against plantpathogenic fungal and bacterial diseases in agriculture in general, few direct data have been presented to demonstrate the role of biofilms by BCA in the biocontrol against root-knot nematodes.

B. cereus AR156 was originally isolated from rhizosphere soil in Nanjing, China. This bacterium exhibited a strong inhibition on egg-hatching and mortality in second-stage juveniles (J2), and good biocontrol efficacy under greenhouse conditions against Meloidognyne incognita (Wei et al. 2010). This BCA was later identified as B. cereus by whole-genome sequencing (GenBank access number CP015589). Strain AR156 has been registered as a BCA and applied for control of root-knot nematodes in China. However, the biocontrol mechanism of AR156 against nematodes is not well understood. Results from our recent study indicated that B. cereus AR156 is capable of forming robust floating pellicles in biofilm-inducing media (Yan et al. 2016). The molecular mechanism governing biofilm formation in this bacterium is largely unknown. Here, we plan to investigate the underlying molecular mechanism that governs biofilm formation in AR156. We are also interested in knowing whether biofilm formation by this bacterium plays a role in the control of root-knot nematodes by this bacterium. Our specific goals include (i) characterizing morphological features of the AR156 biofilms, (ii) investigating the role of the BcspoOA$B c \sin I-B \sin R$ regulatory circuit in governing AR156 biofilm formation, and (iii) exploring the link between biofilm formation and the nematicidal activity in AR156.

\section{RESULTS}

\section{Analyses of candidate genes involved in biofilm formation in AR156.}

In $B$. subtilis, the regulatory network that controls biofilm formation has been well studied (Fig. 1A) (Branda et al. 2005;
Lemon et al. 2008; López et al. 2010; Vlamakis et al. 2013). Using the known biofilm genes in $B$. subtilis as queries, we identified several homologous genes in the AR156 genome encoding highly similar proteins. For example, Spo0A of B. cereus AR156 (designated as $\mathrm{BcSpo0A}$ ) and that of B. subtilis (designated as BsSpo0A) share $81 \%$ identity in amino acid sequence (Supplementary Fig. S1; designation of other B. cereus and B. subtilis genes and proteins was applied similarly in this study). In the $B$. subtilis NCIB3610 genome, there is a locus containing both the biofilm regulatory genes $\sin I-\sin R$ and the matrix operon $\operatorname{tap} A-\operatorname{sip} W$-tasA (Fig. 1B). The corresponding region in the $B$. cereus AR156 genome contains several homologous genes. For example, the encoded BcSinI and $\mathrm{BcSinR}$ proteins share 32 and $64 \%$ identity, respectively, in amino acid sequence with their B. subtilis counterparts (Fig. 1C). Meanwhile, the homologous gene cluster in B. cereus corresponding to the tapA-sipW-tasA operon in B. subtilis shows different composition from the latter. There is no tapA homolog in the genome of AR156; instead, there is a functionunknown hypothetical gene in that region (ORF3431) (Fig. 1B). In addition, this region harbors two tasA-like genes (calY1 and calY2). At the protein level, CalY1 and CalY2, although $57 \%$ identical between each other, share only 28 and $32 \%$ amino acid sequence identity, respectively, with $B$. subtilis TasA. A recent study showed that both CalY1 and CalY2 were critical for formation of submerged biofilms in B. cereus strain CECT148, yet CalY2 was more important than CalY1 in promoting floating pellicles at the air-liquid interface (Caro-Astorga et al. 2015). Our bioinformatics analyses indicated that these two tasA-like genes and the entire gene cluster are highly conserved in various species in the $B$. cereus group, including B. cereus, B. anthracis, and B. thuringiensis.

In addition to the TasA protein fibers, the EPS made by the products encoded in the 15-gene epsA-O operon is another key component of the B. subtilis biofilm matrix (Branda et al. 2001). Previous reports identified similar gene clusters predicted to be involved in capsular polysaccharide biosynthesis (BC5279 to BC5263) in B. cereus ATCC14579 (Ivanova et al. 2003) and EPS biosynthesis (BC5445 to BC5465) in B. cereus B905 (Gao et al. 2015). The latter EPS biosynthesis gene cluster in B. cereus 905 has been shown to not be important for biofilm formation by that bacterium (Gao et al. 2015). Surprisingly, in the B. cereus AR156 genome, we could not identify such a homologous gene cluster based on bioinformatics analysis. We did identify a putative polysaccharide biosynthesis operon but with only eight genes (ORF3769 to ORF3776) (Table 1). Among those putative genes, four (ORF3770, ORF3771, ORF3773, and ORF3774) resemble genes in the eps $A-O$ operon, encoding the bacterial tyrosine kinase modulator EpsA, the EpsB kinase, the oligosaccharide exporter protein EpsK, and the polymerase EpsG, respectively. Another

Table 1. Putative exopolysaccharide biosynthesis genes in gene cluster in Bacillus cereus AR156

\begin{tabular}{|c|c|c|c|c|c|}
\hline $\begin{array}{l}\text { B. cereus } \\
\text { AR156 }\end{array}$ & Predicted function & $\begin{array}{l}\text { Homolog in } \\
\text { B. subtilis } 168\end{array}$ & $\begin{array}{c}\text { Amino acid identity } \\
\text { between AR156 and } 168(\%)\end{array}$ & $\begin{array}{l}\text { Homolog in } \\
\text { B. cereus ATCC14579 }\end{array}$ & $\begin{array}{l}\text { Amino acid identity between } \\
\text { AR156 and ATCC14579 }(\%)\end{array}$ \\
\hline ORF3769 & Acyltransferase & YrhL & 26 & BC1583 & 86 \\
\hline ORF3770 & $\begin{array}{l}\text { Capsule biosynthesis } \\
\text { protein CapK }\end{array}$ & EpsA & 27 & BC1584 & 89 \\
\hline ORF3771 & Tyrosine protein kinase & EpsB & 23 & BC1585 & 87 \\
\hline ORF3772 & $\begin{array}{l}\text { UDP-galactose phosphate } \\
\text { transferase }\end{array}$ & EpsM & 41 & BC1586 & 88 \\
\hline ORF3773 & $\begin{array}{l}\text { Oligosaccharide exporter } \\
\text { protein }\end{array}$ & EpsK & 24 & BC1587 & 94 \\
\hline ORF3774 & $\begin{array}{l}\text { Polysaccharide } \\
\text { polymerase }\end{array}$ & EpsG & 24 & BC1588 & 90 \\
\hline ORF3775 & Glycosyl transferase & TuaG & 46 & BC1589 & 92 \\
\hline ORF3776 & Mannosyl transferase & EpsD & 27 & BC1590 & 90 \\
\hline
\end{tabular}


two genes (ORF3776 and ORF3772) resemble glycosyltransferase genes eps $D$ and eps $M$, respectively. This eight-gene operon is also present in other B. cereus species, including ATCC14579 and B905. The function of this putative operon has not been reported. Taken together, our analyses suggest that EPS biosynthesis in different $B$. cereus strains is likely quite different from that in $B$. subtilis, and may not be well conserved even within the $B$. cereus group.

\section{$\triangle B c s p o 0 A$ and $\Delta B c \sin I$ mutants of AR156 showed decreased biological control efficacy toward root-knot nematode diseases.}

Host colonization by biocontrol agents is the first and critical step during biocontrol, and bacterial colonization on biotic and abiotic surfaces has been shown to be promoted by biofilm formation (Bais et al. 2004; Chen et al. 2013; Haggag and Timmusk 2008). To assess whether biofilm formation by AR156 is important for its biocontrol activity against the nematode, we picked two key regulatory genes, BcspoOA and BcsinI, whose counterparts play essential roles in biofilm formation in B. subtilis (Branda et al. 2001; Chu et al. 2008; Kearns et al. 2005). We constructed $\triangle B$ cspoOA and $\triangle B$ csinI deletion mutants in AR156, and conducted in vitro nematode killing using the wild-type strain and the two mutants. Treatment of $M$. incognita $\mathrm{J} 2$ by cell suspension of AR156 resulted in worm mortality with $97.40 \%$ efficacy in vitro, in comparison with the water control $(P \leq 0.05)$ (Fig. 2A). Both $\triangle B c s p o 0 A$ and $\triangle B c \sin I$ mutants were dramatically attenuated in the ability to kill $M$. incognita J2, with an efficacy of 13.9 and $42.3 \%$, respectively (Fig. 2A). The efficacy reduction in $\triangle B$ cspoOA was more severe than that in $\Delta B$ csinI.

One possible explanation for the reduced killing activity in the $\triangle B c s p o 0 A$ and $\triangle B c \operatorname{cin} I$ mutants was that there was decreased attachment of the mutants to the nematode body surfaces. To test this, we performed an assay to evaluate bacterial attachment to the nematode body surfaces (see Materials and Methods). To explain briefly, B. cereus cells (wild type and mutants) and $\mathrm{J} 2$ nematodes were incubated in Eppendorf tubes for $24 \mathrm{~h}$ at room temperature. J2 were picked up by needles under a stereomicroscope and suspended in sterilized water. Body surface-associated bacterial cells were washed off and plated on Luria-Bertani (LB) agar media to count CFU. The number of recovered bacterial cells (normalized to one J2) was significantly lower in the treatments of the two mutants than that of the wild-type AR156 (an approximately fourfold decrease) (Fig. 2B). Thus, bacterial attachment to the nematodes is impaired in both the $\triangle B \operatorname{cspoOA}$ and $\triangle B c \sin I$ mutants. This is possibly due to their inability to form biofilms because biofilms often possess strong adhesive properties on worm body surfaces (Atkinson et al. 2011; Darby et al. 2002; Drace and Darby 2008; Joshua et al. 2003).

Next, we compared biological control efficacy of the wildtype AR156 and the $\triangle B c s p o O A$ and $\triangle B c \sin I$ mutants on tomato plants. In the biocontrol experiments, the sterilized sandy loam soil treated with AR156 cells effectively suppressed the rootknot development on tomato roots and obtained nearly $65 \%$ biocontrol efficacy in comparison with the nonbacterial treatment (Fig. 2C). Application of the $\triangle B c s p o 0 A$ or the $\Delta B c \sin I$ mutant resulted in a significant reduction in disease control (23 and $38 \%$, respectively) (Fig. 2C). The biocontrol efficacy of $\triangle B c s p o 0 A$ was even lower than that of $\triangle B c \sin I$, in line with the results from assays of nematode killing (Fig. 2A).

To test whether the reduction in the biocontrol activity in the mutants was caused by lowered bacterial colonization, the population dynamics of the wild type and the two mutants in the tomato rhizosphere was monitored over a period of 56 days by the plating method. Overall, the cell population of all three strains in the rhizosphere decreased incessantly in the first week and stabilized after 7 days postinoculation (dpi) (Fig. 2D). For instance, the wild-type cell population declined from $1.57 \times 10^{8} \mathrm{CFU} / \mathrm{g}$ of rhizosphere soil at the beginning of the experiment to $1.55 \times 10^{7} \mathrm{CFU} / \mathrm{g}$ of soil after 1 week and stabilized afterward to approximately $10^{7} \mathrm{CFU} / \mathrm{g}$ of soil (at 14, 21, 30, 40, and $56 \mathrm{dpi}$, the total numbers of cells were 2.04, $1.58,1.95,2.04$, and $1.26 \times 10^{7} \mathrm{CFU} / \mathrm{g}$ of rhizosphere soil, respectively) (Fig. 2D). In comparison with the wild type, the $\triangle B c$ spoOA and $\triangle B c \sin I$ mutants showed a seven- and threefold reduction, respectively, in the total number of root-associated cells after 1 week, which was in the range of $10^{6} \mathrm{CFU} / \mathrm{g}$ of rhizosphere soil. Noticeably, the cell number of $\triangle B c \sin I$ in the rhizosphere soil was approximately twofold higher than that of $\triangle B$ cspoOA (Fig. 2D).

Together, our results suggest that BcspoOA and BcsinI and, likely, the biofilm formation controlled by them play critical roles in the bacterial colonization of the nematode body surface and in bacterial survival in the rhizosphere, both of which subsequently promote biocontrol activity against root-knot
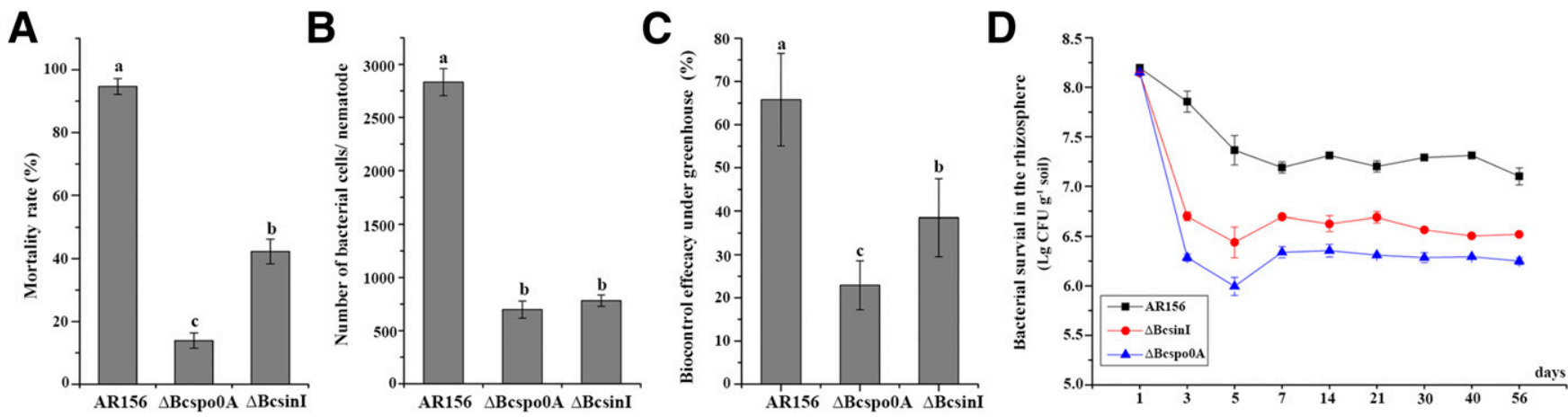

Fig. 2. Both the BcspoOA and BcsinI genes are important for the nematicidal activity, root colonization, and biological control against Meloidogyne incognita by Bacillus cereus AR156. A, Assays of the mortality rate of $M$. incognita in treatments of the wild type and the $\triangle B c s p o 0 A$ and $\triangle B c$ sinI mutants. Juveniles were cocultured with cell suspension of the wild type or the two mutants and incubated at room temperature. After $12 \mathrm{~h}$, live and dead worms were counted using stereoscopy. B, Colonization capability of the wild type and the two mutants on the body surface of the worms. Juveniles in each treatment were picked and resuspended with sterilized water after coculture. Suspension was serial diluted and cultured on the Luria-Bertani agar medium for CFU counting. CFU was normalized per juvenile. $\mathbf{C}$, Biocontrol efficacy of the wild type and two mutants against tomato root-knot nematode diseases under greenhouse conditions. The average \pm standard deviation was calculated from three independent trials and analyzed using Student's $t$ test $(P \leq 0.05)$. In A, B, and C, bars marked with different letters indicate that there was a significant difference. D, Population density of AR 156 and the $\triangle B$ cspoOA and $\triangle B c s i n I$ mutants in the rhizosphere monitored over a period of 56 days in the biocontrol experiment against root-knot nematode diseases. Root-associated bacterial cells were collected periodically and CFU of the samples was determined by a conventional plating method. 
nematodes. Therefore, we decided to further investigate the role of BcspoOA and BcsinI in biofilm formation in B. cereus AR156.

\section{BcsinI was required}

\section{for biofilm formation and swarming motility in AR156.}

Because SinI is a key positive regulator for biofilm formation in B. subtilis, we were curious about whether the SinI homolog in $B$. cereus has a similar function. To test this, we compared pellicle biofilm formation by the $\Delta B c \sin I$ mutant to that of the wild-type strain. Cells were inoculated in a biofilm-inducing medium, LB supplemented with $1 \%$ glycerol and $200 \mu \mathrm{M}$ $\mathrm{MnSO}_{4}$ (LBGM) (Shemesh and Chai 2013), and incubated at $25^{\circ} \mathrm{C}$. After $72 \mathrm{~h}$ of incubation, wild-type cells formed robust pellicle biofilms at the air-liquid interface, whereas the $\Delta B c \sin I$ mutant was unable to form a strong pellicle (Fig. 3A, left-hand panels), even after incubation for 10 days (data not shown). The total biomass of the pellicle by the $\Delta B \operatorname{csin} I$ mutant was 14 -fold less when compared with that of the wild-type pellicle (Fig. 3B). To further gain insight into the morphological details of the wild-type pellicles (or thin floating films in the case of the $\Delta B c \sin I$ mutant), pellicles by both the wild type and the $\Delta B \operatorname{csin} I$ mutant were harvested and imaged using scanning electronic microscopy (SEM). Cells in the wild-type pellicles were tightly stuck together and individual cells were heavily cross-linked by a web-like matrix (Fig. 3A, upper middle and right-hand panels). In contrast, only very short filamentous fibrils were seen on the cell surfaces of the $\Delta B c \sin I$ mutant and little web-like matrix was seen in the pellicles prepared from that mutant (Fig. $3 \mathrm{~A}$, middle and right-hand panels).

Motility of the bacterial biocontrol agents has been suggested as an important factor in bacterial colonization on plant host surfaces (Andersen et al. 2003; Gao et al. 2016). We briefly tested swarming motility of the wild-type strain and the $\Delta B c \sin I$ mutant on $0.7 \%$ LB agar plates. The result showed that the $\Delta B c \sin I$ mutant had a reduced swarming capability (Fig. $3 \mathrm{C}$ and D). Note that no growth defect was seen in the $\Delta B c \sin I$ mutant (Supplementary Fig. S2). Thus, we concluded that, in B. cereus AR156, SinI is critical for biofilm formation, similar to what was seen in B. subtilis (Kearns et al. 2005). In addition, SinI also seems to be important for swarming motility in B. cereus AR156, a feature different from that in $B$. subtilis.

\section{$B$ csinI can functionally replace $B s s i n I$ in regulating biofilm formation in $B$. subtilis.}

Previous studies showed that, in B. subtilis, disruption of $\operatorname{sinI}$ caused a severe biofilm defect (Kearns et al. 2005). Our results above indicated that $\sin I$ is essential in biofilm formation in B. cereus (Fig. 3A). Because both SinI proteins share sequence similarity (Fig. 1C), we wondered whether BcSinI could functionally substitute for $B$. subtilis SinI. To test our hypothesis, we performed heterologous expression of the BcsinI gene at an ectopic amyE locus in a B. subtilis $\Delta B \operatorname{ssinI}$ mutant, and examined the biofilm phenotype of the engineered strain. The $B c \sin I$ gene was fused with the $g f p$ gene for green fluorescent protein (GFP) for easy detection of gene expression and protein production. The expression of $g f p-B c \sin I$ was driven by a strong and constitutively expressed hyperspank promoter (Britton et al. 2002). A similar $g f p$-BssinI fusion (sinI from B. subtilis) was constructed previously and used as a positive control here (Chai et al. 2010). The wild-type B. subtilis 3610 displayed robust colony architecture on the LBGM agar plate and formed wrinkled pellicles in the LBGM liquid medium (Fig. 4A), consistent with the previous study (Shemesh and Chai 2013). As expected, the $\Delta B$ ssinI mutant completely lost the ability to form pellicle biofilms and showed flat colony morphology in LBGM (Fig. 4B). Overexpression of the $g f p$-BssinI fusion completely rescued the biofilm defect caused by $\Delta B \sin I$ (Fig. $4 C)$. Interestingly, overexpression of $g f p-B c \sin I$ also complemented $\Delta B$ ssinI in biofilm formation (Fig. 4D), although the colony morphologies by the two overexpression strains somewhat differed from each other (Fig. 4C and D). These results indicate that $B \sin I$ can functionally replace $B \sin I$ in regulating biofilm formation in $B$. subtilis.

In $B$. subtilis, the interactions between the biofilm master repressor BsSinR and the antagonist BsSinI have been well studied biochemically and structurally (Colledge et al. 2011). The full-length BsSinI (amino acids 1 to 57) shares strong sequence similarity with the C-terminal domain of BsSinR (amino acids 60 to 115) (Fig. 1D). In the cocrystal structure of the SinI-SinR complex, amino acid residues 3 to 39 of BsSinI and the residues 74 to 111 of BsSinR form an intermolecular four-helix bundle, in which each chain contributes a pair of helices that hook together. Eight conserved apolar residues are integral to or surrounding the intermolecular hydrophobic core and critical to the interaction (Fig. 1D, highlighted in red in the upper panel) (Colledge et al. 2011). Many of those residues in BsSinI involved in interactions with BsSinR are also conserved in BcSinI (Fig. 1D, highlighted in red in the lower panel). Thus, it is possible that BcSinI can interact with and antagonize B. subtilis SinR due to sequence (and possibly structural) similarity to its $B$. subtilis counterpart. Just like the counterparts in B. subtilis, BcSinR and BcSinI are also similar to each other, with conserved interaction sites seen in the B. subtilis counterparts (Fig. 1D, lower panel). Our protein sequence and domain analyses indicate that the BcSinR-BcSinI interaction in B. cereus may be similar to that of their orthologs in B. subtilis. We also speculate that BcSinI may cross-interact with BsSinR due to its similarity to BsSinI, which explains why BcSinI can functionally replace BsSinI in the regulation of biofilm formation in B. subtilis.

In $B$. subtilis, BsSinR, together with another regulatory protein SlrR, negatively controls genes for matrix production while it positively regulates those for cell separation (Chai et al. 2009; Chu et al. 2008). In other words, antagonizing SinR activities is expected to derepress matrix genes to achieve robust biofilm formation while simultaneously shutting off cell separation genes (e.g., genes encoding various autolysins) for formation of cell chains and bundles, which likely function as a scaffold for biofilm assembly (Chai et al. 2010). Consistent with the above proposed regulation, we observed that overexpression of $g f p-B \sin I$ in $\Delta B \sin I$ not only rescued the biofilm defect but also caused extensive cell chaining, likely due to SinR antagonization and downregulation of cell separation genes (Fig. 4E). The complementation strain by overexpression of $g f p-B c \sin I$ in $\Delta B \sin I$ also showed a chaining phenotype. Intriguingly, it formed much shorter and bent cell chains when compared with that of the $g f p$-BssinI-complemented strain (Fig. $4 \mathrm{~F})$. Moreover, the average size of individual cells in the short chains of the $g f p$-BcsinI-complemented strain was significantly smaller than that of cells in the chains of the $g f p$-BssinIcomplemented strain (Fig. 4E and F; Supplementary Fig. S3). To better measure the cell size of above strains, cells were prepared and observed with SEM. Consistent with the results from fluorescent microscopy, the complementation strain overexpressing $g f p$-BssinI formed long cell chains, whereas the $g f p$ $B c \sin I$ overexpression strain displayed chains that were much shorter (Fig. 5A to D). Furthermore, cells of the $g f p$-BssinI complementation strain $(4.58 \pm 0.36 \mu \mathrm{m})$ were bigger in size than the wild-type $3610(2.16 \pm 0.20 \mu \mathrm{m}), \Delta B \operatorname{ssinI}(1.73 \pm 0.28 \mu \mathrm{m})$, and the $g f p-B c \sin I$ overexpression strain $(1.72 \pm 0.17 \mu \mathrm{m})$ (Fig. $5 \mathrm{E})$. The difference between the two $\sin I$ overexpression strains was not likely to be due to differential production of the two fusion proteins because cells overexpressing $g f p$-BssinI and 
those of $g f p-B c \sin I$ demonstrated similar fluorescence intensity (Fig. 4E and F). Considering that the amino acid sequence identity between $\mathrm{BsSinI}$ and $\mathrm{BcSinI}$ is only $32 \%$, we presumed that BcSinI may have another unknown cellular target (other than BsSinR) in B. subtilis that is involved in cell size control. Alternatively, BsSinR controls cell size through a yet-unknown mechanism in B. subtilis and the antagonization efficacy of BsSinI against BsSinR is better than that of BcSinI.
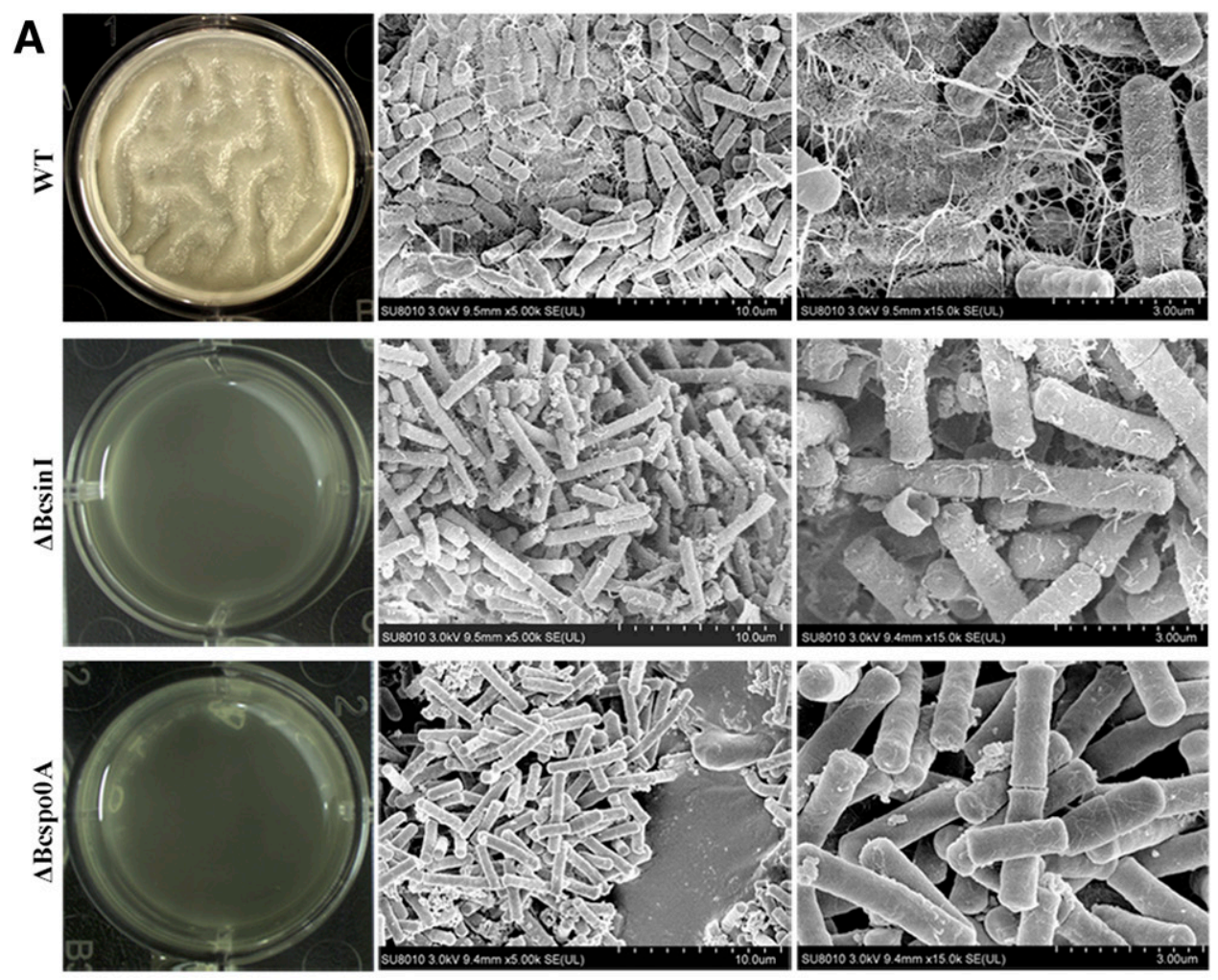

B

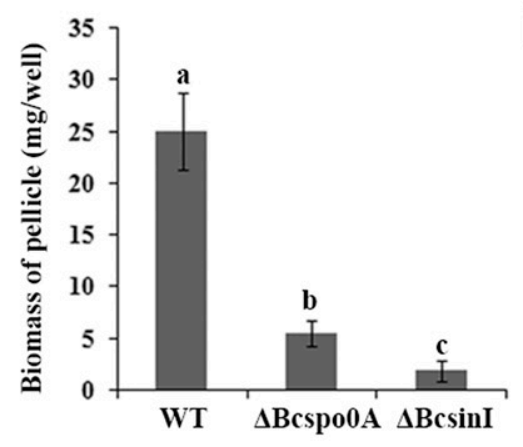

D

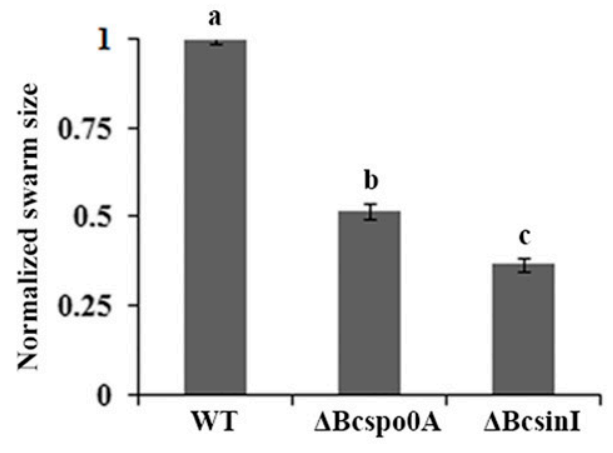

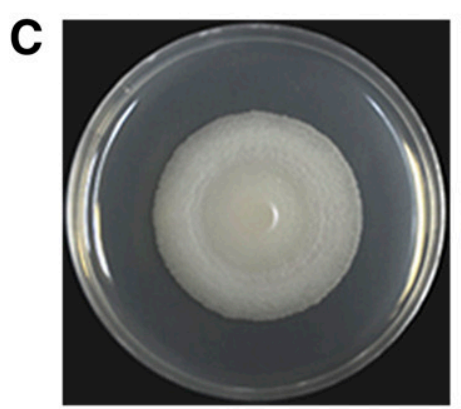

WT

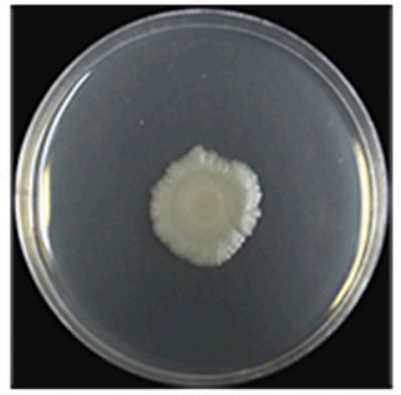

$\triangle \mathrm{Bcspo0A}$

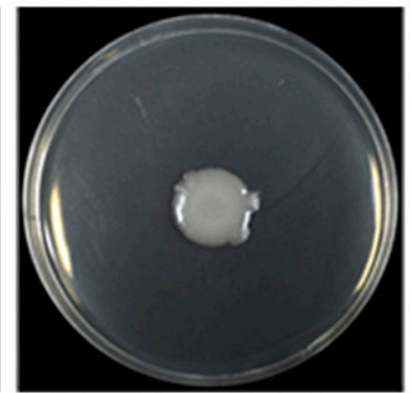

$\Delta \mathrm{BcsinI}$

Fig. 3. BcsinI and BcspoOA mutants are defective in pellicle formation and swarming motility. A, The wild type (WT) and the $\triangle B$ csinI and $\triangle B c s p o O A$ mutants were grown in Luria-Bertani (LB) agar supplemented with $1 \%$ glycerol and $200 \mu \mathrm{M} \mathrm{MnSO}_{4}$ for 3 days at $30^{\circ} \mathrm{C}$ in 12 -well plates before images were taken (lefthand panels). Morphological details of the pellicles were visualized by scanning electron microscopy at $\times 5,000$ (middle panels) and $\times 15,000$ (right-hand panels) magnifications. B, Biomass of the pellicles formed by the WT or the $\Delta B c \operatorname{sinI}$ and $\triangle B c S p o 0 A$ mutants. The 3-day pellicles were harvested from four individual wells for each strain and air dried prior to measurement of dry weight. Experiments were repeated three times. $\mathbf{C}$, Swarming motility of the WT and the $\triangle B c \operatorname{sinI}$ and $\triangle B c S p o 0 A$ mutants. Strains were inoculated on the $0.7 \% \mathrm{LB}$ agar plates and incubated at $30^{\circ} \mathrm{C}$ for $12 \mathrm{~h}$ before images were taken. $\mathbf{D}$, Size of the swarming zone on the plates inoculated with either the $\triangle B$ csinI or the $\triangle B c s p o 0 A$ mutant was normalized against that of the WT. All values are the average of three replicates. Bars marked with different letters indicate a significant difference according to a least significant difference test at $P=0.05$. 
$B \operatorname{ssin} R$ was also functionally replaceable by $B c \sin R$ in biofilm regulation in $B$. subtilis.

BsSinR is a biofilm master repressor in B. subtilis (Chu et al. 2006; Kearns et al. 2005). The B. subtilis mutant of $\sin R$ $(\Delta B \sin R)$ showed a robust biofilm phenotype in LBGM and even in LB, a medium less favorable for biofilm induction (Fig. 6B). Because construction of the knockout mutant of BcsinR in AR156 was not successful, we decided to apply heterologous expression of $B c \sin R$ in $B$. subtilis to see whether $B c \sin R$ can functionally substitute for $B \sin R$ in $B$. subtilis, similar to what we did for BcsinI. In our previous study, we showed that, in B. subtilis, by providing a wild-type copy of $\sin R(B \sin R$ with its own native promoter) at the ectopic amy $E$ locus, it not only complemented $\triangle \sin R$ but further downregulated the expression of SinR-repressed matrix genes, resulting in a severe biofilm defect (Chai et al. 2011). This is likely due to both an increased gene dose of $\sin R$ when complemented at the replication origin-proximal amyE locus $\left(28^{\circ}\right)$ compared with the origin-distal native locus $\left(218^{\circ}\right)$ and ultrasensitivity of SinR-repressed genes to the protein levels of SinR (Chai et al. 2011). As expected, the complemented strain with $B \sin R$ at $a m y E$ in $\triangle B \sin R$ displayed smooth, featureless colony morphology and a severe defect in pellicle biofilm formation (Fig. 6C). Interestingly, the complementation strain by $B c \sin R$ had a nearly identical biofilm phenotype (Fig. 6D), suggesting that $B c \sin R$ can substitute $B \sin R$ in biofilm regulation in $B$. subtilis. This was somewhat expected based on high amino acid sequence identity between BcSinR and BsSinR (64\%), especially in their N-terminal DNA-binding domains (Fig. 1C). This also suggests that BsSinR and BcSinR may recognize similar DNA motives in transcriptional regulation. Indeed, the consensus DNA sequences recognized by BsSinR (GTTCTCT, SinR box) (Chu et al. 2008) were also seen arranged in tandem repeats in the regulatory regions of the sipW, orf3431, and calY2 genes in B. cereus AR156, with a few variations (Figs. 1B; Supplementary Fig. S4). Taken together, our results suggested that BsSinR was also functionally replaceable by $\mathrm{BcSinR}$ in biofilm regulation in B. subtilis and that, possibly, BsSinR and BcSinR
A

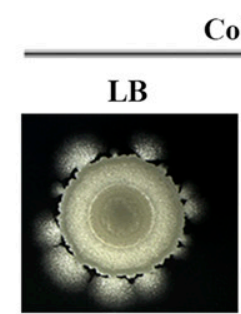

B

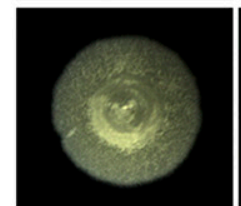

C

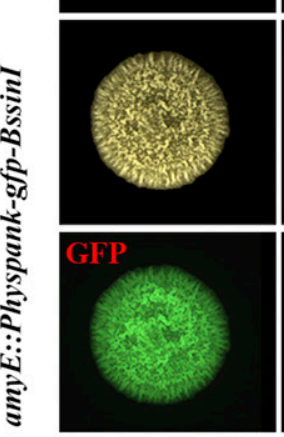

D

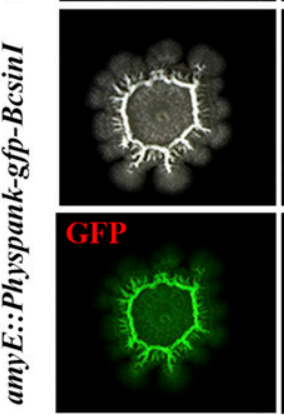

Colony
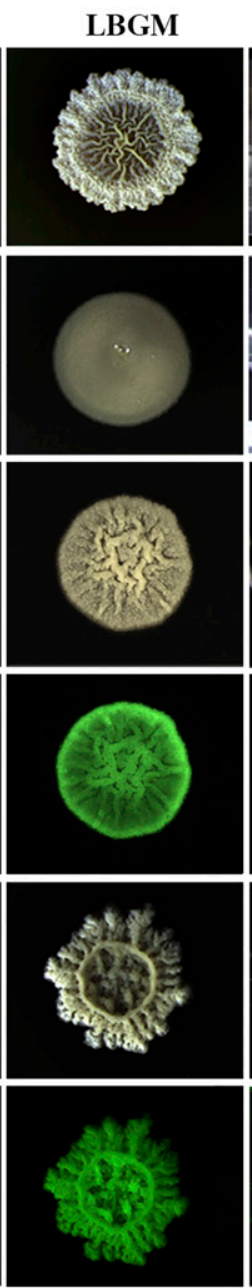

Pellicle
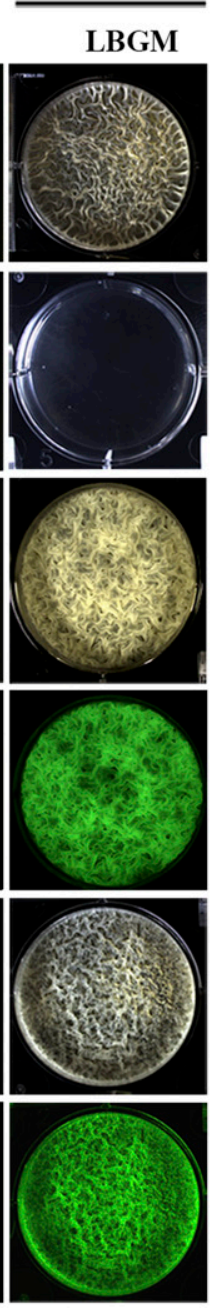

$\mathbf{E}$
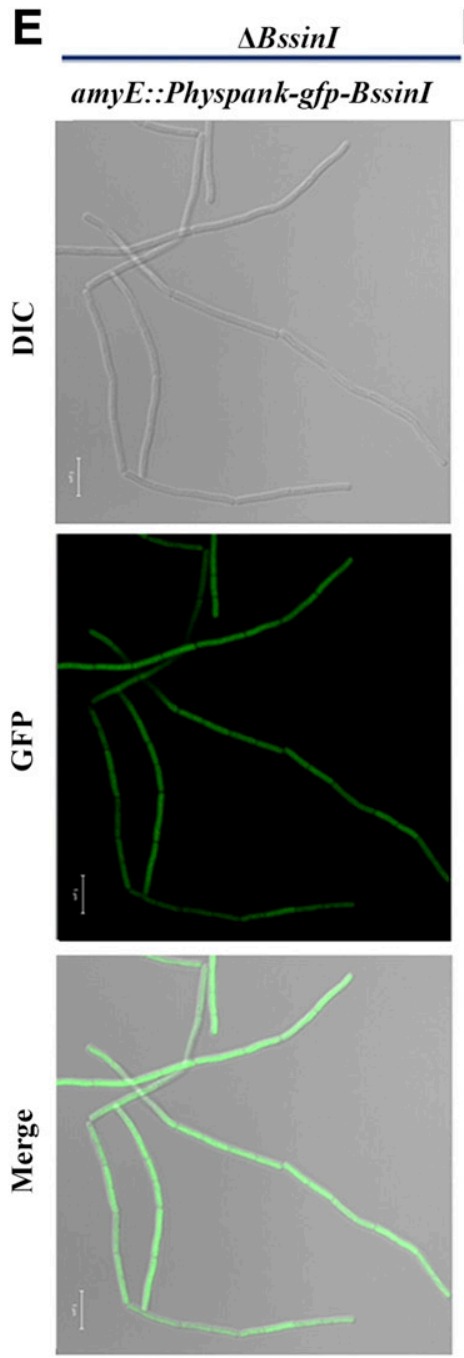

$\mathbf{F}$ $\frac{\Delta B s s i n I}{\text { amyE::Physpank-gfp-BcsinI }}$


Fig. 4. Heterologous expression of Bacillus cereus $\sin I$ in the B. subtilis $\Delta B s \sin I$ mutant rescued the biofilm defect. Colony biofilm and pellicle formation by $\mathbf{A}$, the wild type B. subtilis $3610 ; \mathbf{B}, \Delta B \sin I$; and $\mathbf{C}$ and $\mathbf{D}$, indicated heterologous complementation strains in Luria-Bertani (LB) agar or LB supplemented with $1 \%$ glycerol and $200 \mu \mathrm{M} \mathrm{MnSO}_{4}$ (LBGM). Images were taken after 3 days of incubation at $25^{\circ} \mathrm{C}$. To compare green fluorescence intensity, colonies or pellicles formed by cells bearing either the $g f p-B \sin I$ or the $g f p-B c \sin I$ fusion were visualized by fluorescent dissecting microscope. Microscopic analyses of the cell chaining phenotype in E, YC227 ( $\Delta$ BssinI, $P_{\text {hyspank }}$-gfp-BssinI) and F, CY617 ( $\Delta$ BssinI, $P_{\text {hyspank }}$ - $g f p$-BssinI). Shown were phase contrast, green fluorescence, and merged images (from top to bottom). Cells were grown in LBGM medium to an optical density at $600 \mathrm{~nm}=1.0$, harvested, and observed by confocal microscopy. Scale bars: $5 \mu \mathrm{m}$. 
recognize nearly identical operator sequences in the regulatory regions of their controlled genes. Furthermore, BcSinI and BcSinR may cross-interact with their counterpart repressor and antirepressors in B. subtilis. Finally, although we do not have direct evidence yet, we speculate that BcSinI and $\mathrm{BcSinR}$ may possess regulatory functions in B. cereus AR156 biofilm formation similar to their counterparts in B. subtilis.
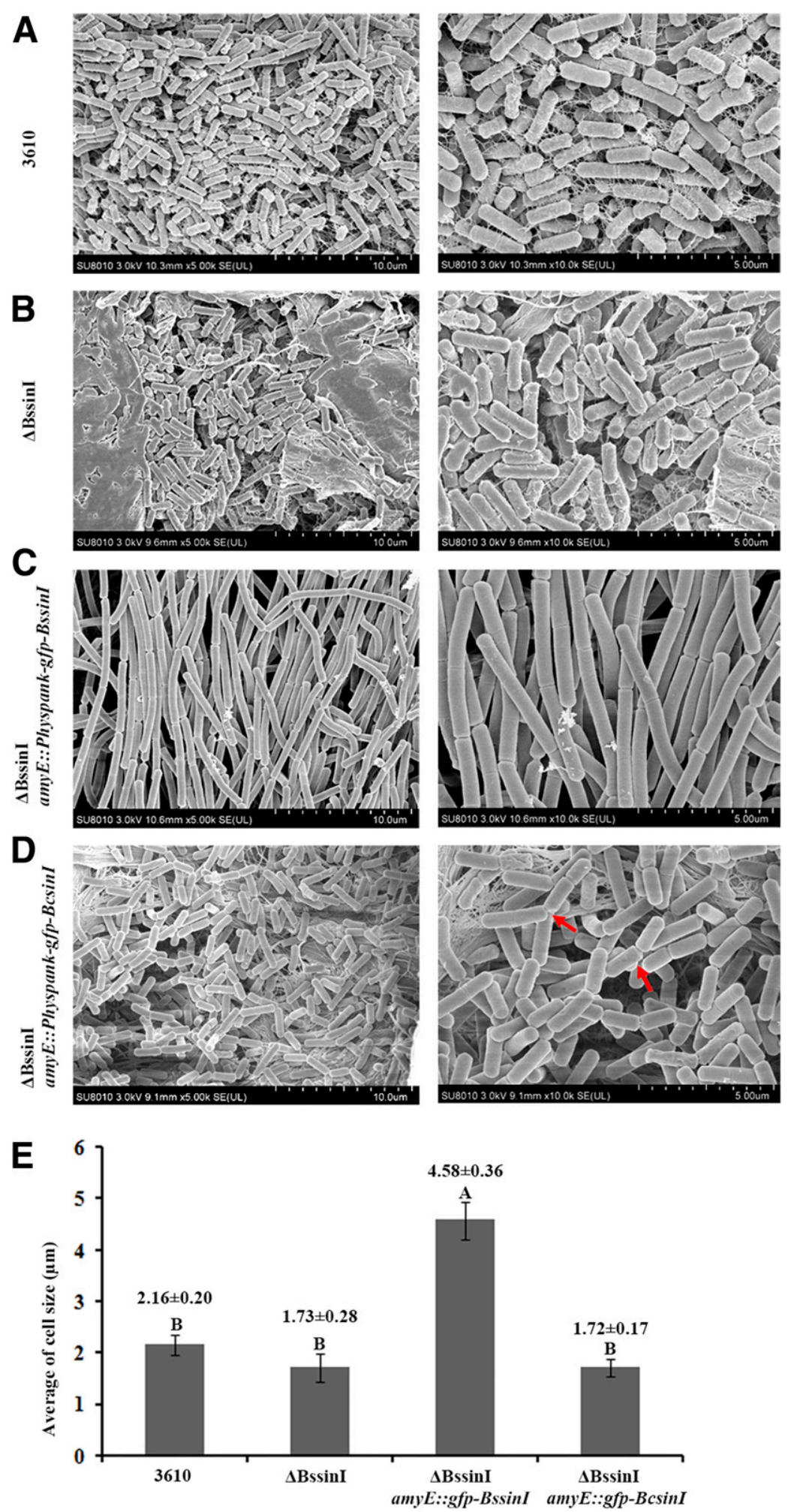

Fig. 5. Heterologous expression of Bacillus cereus $\sin I$ in the B. subtilis $\Delta B \operatorname{ssinI}$ mutant reduced the cell size. A, The wild type; B, FC333 ( $\triangle B$ ssinI); C, YC227 $\left(\Delta B \operatorname{ssinI}, P_{\text {hyspank }}\right.$-gfp-BssinI); and D, CY617 ( $\Delta B s \operatorname{sinI}, P_{\text {hyspank }}$-gfp-BssinI) were grown in Luria-Bertani agar supplemented with $1 \%$ glycerol and $200 \mu \mathrm{M}$ $\mathrm{MnSO}_{4}$ to an optical density at $600 \mathrm{~nm}=1.0$, and visualized by scanning electron microscopy at $\times 5,000$ (left panels) and $\times 10,000$ (right-hand panels) magnifications. The arrow indicates the shorter chaining. E, Average cell size was measured and analyzed. Average \pm standard deviation was calculated from three independent trials and analyzed using Student's $t$ test $(P \leq 0.01)$. Bars marked with different letters indicate that there was a significant difference. 


\section{Bcspo0A was essential}

in cell differentiation in B. cereus AR156.

BsSpo0A plays a central role in cell differentiation in B. subtilis (Branda et al. 2001; Hoch 1993). A $\triangle$ spoOA mutant of $B$. subtilis was completely deficient in both sporulation and biofilm formation (Fig. 7C and E) (Branda et al. 2001, 2006). In contrast, few studies have demonstrated the importance of Spo0A in cell differentiation in B. cereus (Gao et al. 2015). Thus, we examined phenotypes in cell differentiation by the $\triangle B$ cspoOA deletion mutant of AR156. Similar to the B. subtilis $\triangle B$ sspo0A mutant, no pellicle biofilm was observed by the $\triangle B$ cspo0A mutant of AR156 in LBGM (Fig. 3A). Further examination by SEM revealed that, contrary to the wild type, the pellicles by the $\triangle B$ cspoOA mutant completely lacked the web-like matrix holding individual cells together (Fig. 3A). This was similar to what was observed in the $\Delta B \operatorname{csinI}$ mutant (Fig. 3A). Thus, BcspoOA was also essential for biofilm formation in $B$. cereus AR156. The $\triangle B$ cspoOA mutant also showed a defect in swarming motility, though slightly less severe than that of the $\Delta B \operatorname{csinI}$ mutant (Fig. $3 \mathrm{C}$ and $\mathrm{D}$ ).

We also examined sporulation efficiency for the wild-type AR156 and the $\triangle B$ cspoOA mutant. When the $\triangle B$ cspoOA cells were grown in Difco sporulation medium for $36 \mathrm{~h}$, only rodshaped cells but not spores were observed, whereas the wildtype AR156 cells formed mostly phase-bright spores under the same condition (Fig. 7A). Cells of both the wild type and the $\triangle B$ cspo0A mutant were also harvested after $36 \mathrm{~h}$ of growth in Difco sporulation (DS) medium and observed by transmission electron microscopy (TEM) to gain more structural details of the cells. The wild-type AR156 spores contained dense inclusions and were dark under TEM (Fig. 7B). In contrast, the $\triangle B$ cspoOA cells showed vegetative cell-like rod shape and had less density and darkness in the cytosol (Fig. 7B). The heat kill experiment was further conducted to compare the ratio of heatresistant spores between the wild type and the $\triangle B$ cspoOA mutant. The result was consistent with the observations under a microscope, showing that the wild-type culture contained almost $100 \%$ heat-resistant spores after $36 \mathrm{~h}$ of incubation in DS medium, whereas virtually no viable cells were recovered from the $\triangle B$ cspoOA culture after heat treatment. This confirms that BcspoOA is also essential for sporulation in B. cereus AR156.

\section{Heterologous expression of $B c s p o 0 A$ rescued the sporulation and biofilm defects in the B. subtilis $\triangle B$ sspo0A mutant.}

Because the $\triangle B$ cspoOA mutant of $B$. cereus AR156 displayed phenotypes in cell differentiation similar to those of the $\triangle B$ sspoOA mutant of $B$. subtilis and because the two Spo0A proteins share very high amino acid sequence identity $(80 \%)$, we speculated that these two proteins might be interchangeable in regulating cell
A
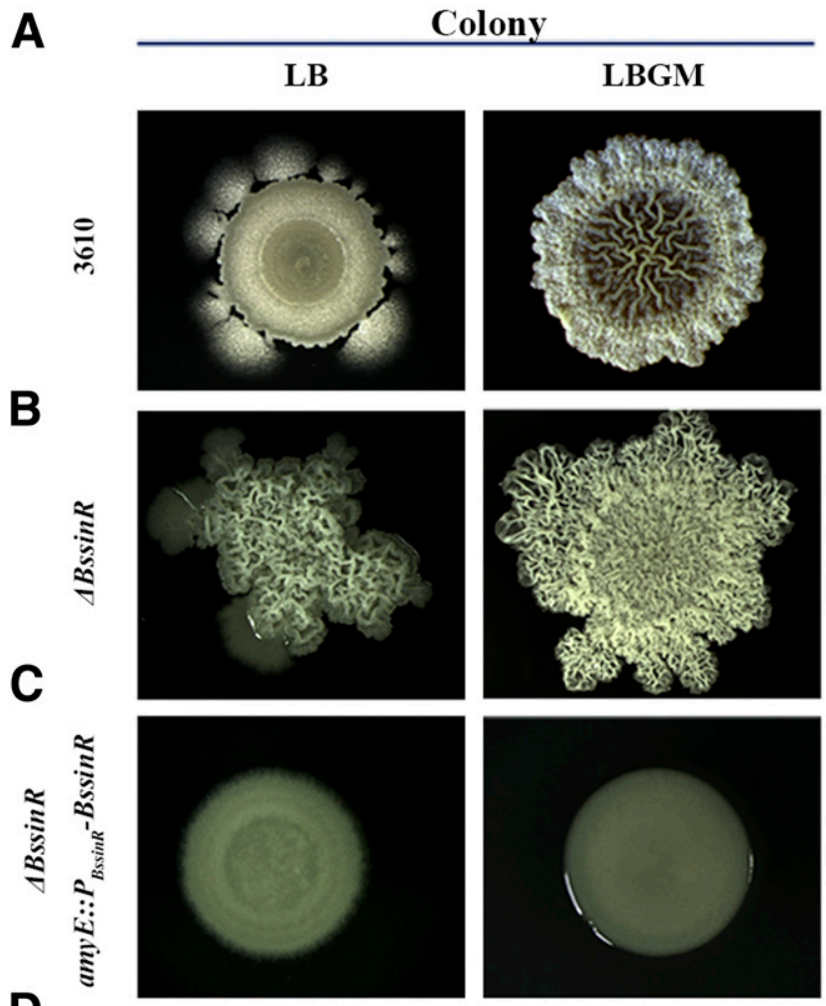

$\mathbf{D}$
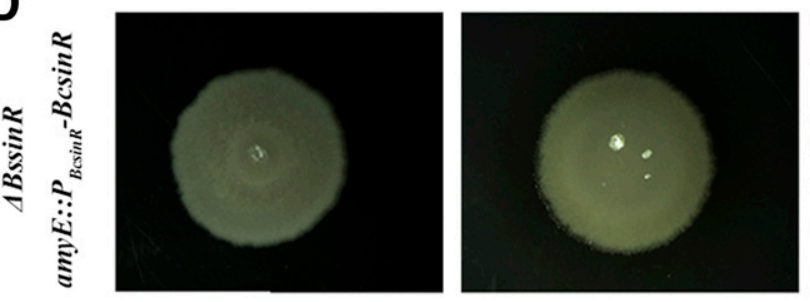
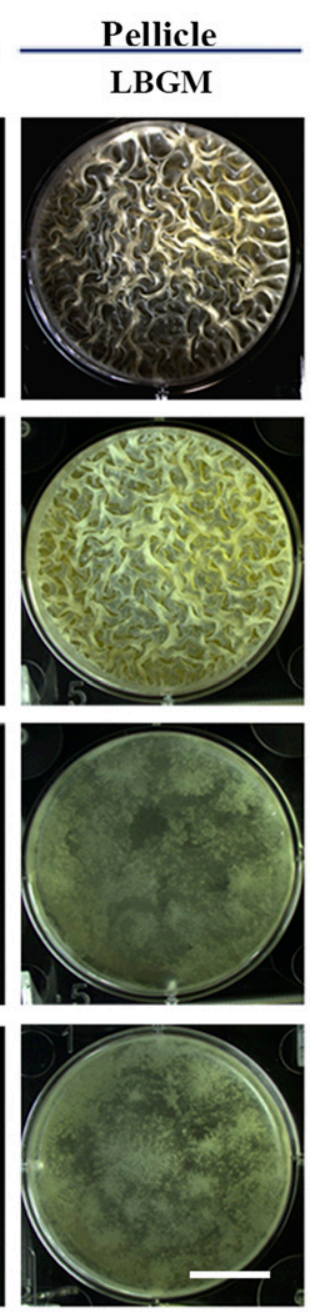

Fig. 6. Bacillus cereus $\sin R$ can replace B. subtilis $\sin R$ in biofilm regulation in $B$. subtilis. Colony biofilm and pellicle formation by A, the wild-type $B$. subtilis $3610, \mathbf{B}, \Delta B \sin R$, and complementation strains expressing either $\mathbf{C}, B \sin R$ or $\mathbf{D}, B c \sin R$ in Luria-Bertani (LB) agar or LB supplemented with $1 \%$ glycerol and $200 \mu \mathrm{M} \mathrm{MnSO}_{4}(\mathrm{LBGM})$. Images were taken after 3 days of incubation at $25^{\circ} \mathrm{C}$. Scale bar: $1 \mathrm{~cm}$. 
differentiation. To test this, we expressed $B c s p o 0 A$ under the control of the BsspoOA native promoter $\left(P_{B s s p o 0 A}-B c s p o 0 A\right)$ in the $\triangle B$ sspoOA strain of $B$. subtilis and examined whether the heterologous expression of $B c s p o O A$ could rescue the defects of sporulation and biofilm formation by $\triangle B s s p o 0 A$. Interestingly, the heterologous expression strain was completely rescued for the ability to sporulate (Fig. 7C) and to form robust biofilms (Fig. 7E). There was virtually no difference in biofilm formation between the heterologous expression strain with BcspoOA and the complementation strain with BsspoOA (Fig. 7E). Hence, we conclude that Spo0A proteins are not only conserved in amino acid sequence in both $B$. cereus and $B$. subtilis but also structurally similar enough

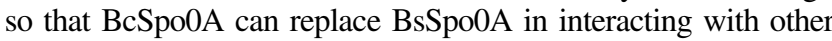
partner proteins and in regulating cell differentiation in the heterogeneous host $B$. subtilis.

One more interesting observation we had was that the wildtype 3610 and the $\triangle B$ sspoOA mutant of 3610 grew similarly in
DS medium before reaching late log phase (optical density at $600 \mathrm{~nm}\left[\mathrm{OD}_{600}\right]=1.0$ ). However, after reaching late log phase, the culture density of the $\triangle B$ sspoOA mutant rapidly dropped and eventually reached $\mathrm{OD}_{600}=0.1$ (a 10-fold decrease) after $36 \mathrm{~h}$ of shaking growth, while the wild-type culture reached $\mathrm{OD}_{600}$ of approximately 2 (a 2 -fold increase) after the same shaking growth (Fig. 7D). There was a strong cell lysis phenotype associated with stationary phase cells of the B. subtilis $\triangle$ spoOA mutant. Remarkably, such a strong cell lysis phenotype was not seen in the B. cereus spo0A mutant, where the cell density of the $\triangle B$ cspoOA mutant was still retained at $\mathrm{OD}_{600}=2.0$. Moreover, the cell lysis phenotype of in $\triangle B$ sspoOA can be rescued by heterologous expression of BcspoOA (Fig. 7D). We hypothesized that the sporulationdefective $\triangle B$ cspoOA cells experience less autolysis in nutrientlimiting conditions compared with the similar mutant in B. subtilis.
A

B
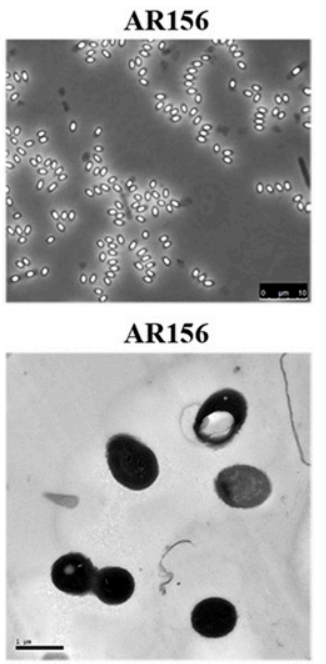

C
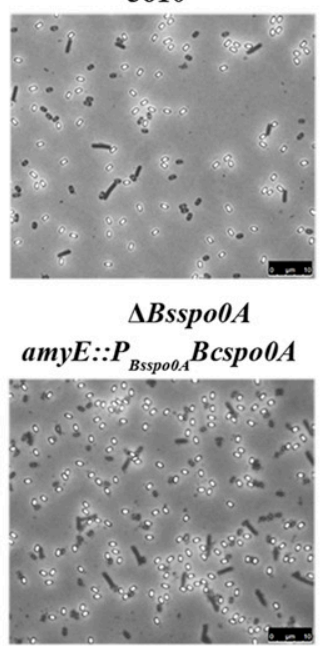

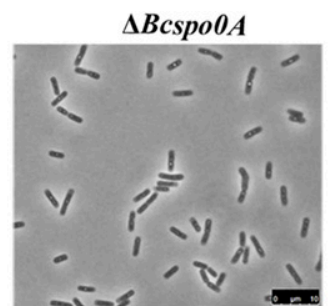

$\triangle B \operatorname{cspo0A}$

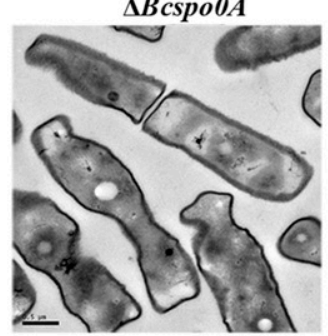

$\triangle B$ sspo0A

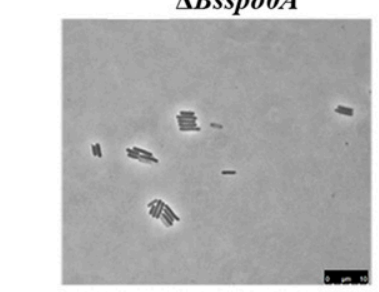

D

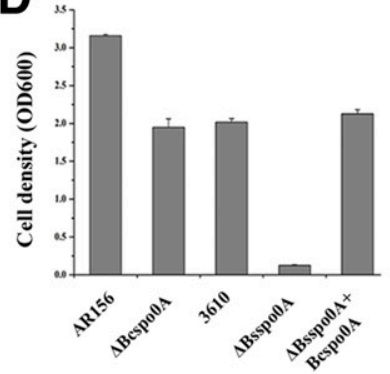

E
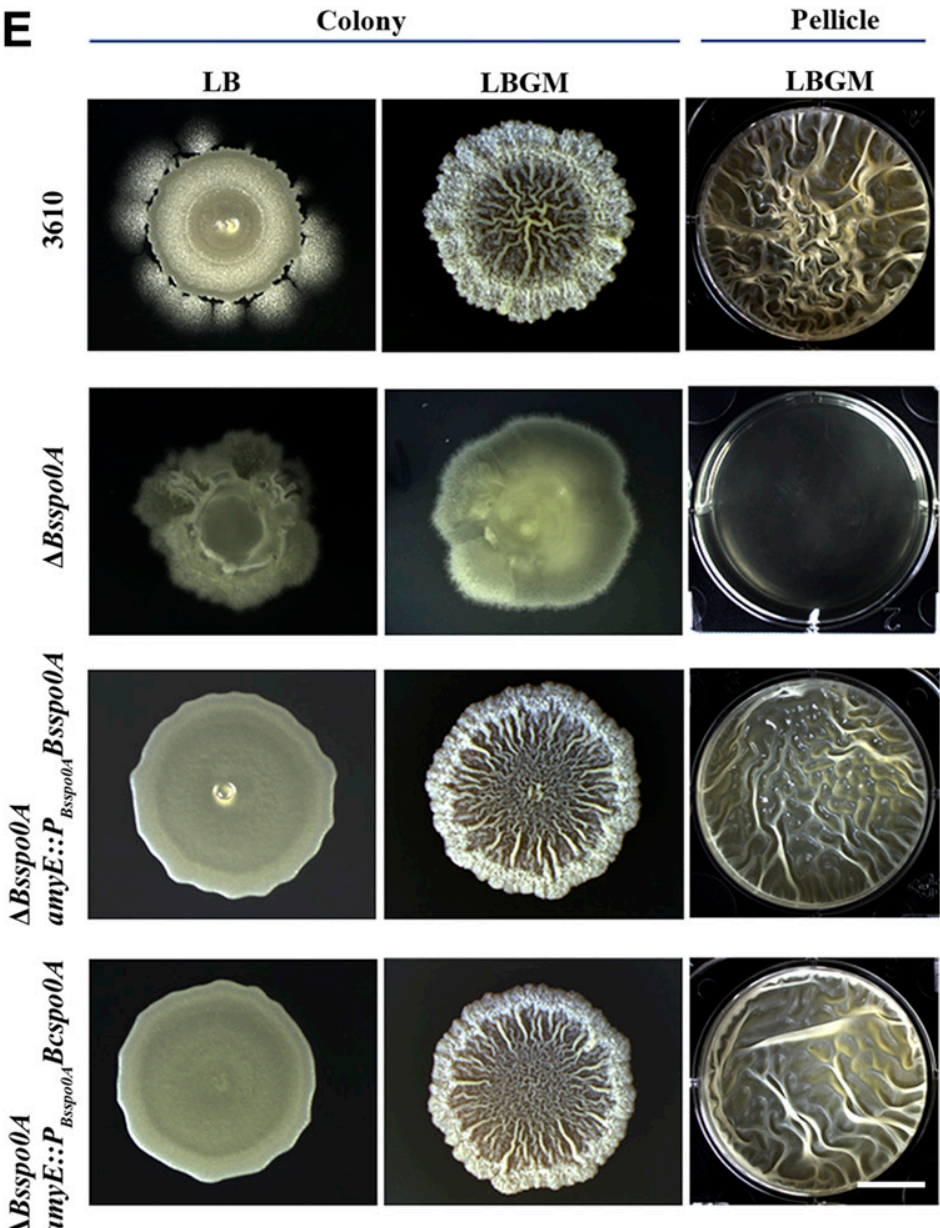

Fig. 7. Bcspo0A was essential for sporulation and biofilm formation in Bacillus cereus AR156. A, The Bcspo0A deletion mutation completely abolished formation of heat-resistant spores in $B$. cereus AR156. The wild-type strain and the $\triangle B$ cspoOA mutant were grown in the Difco sporulation (DS) medium for $36 \mathrm{~h}$ at $37^{\circ} \mathrm{C}$ under shaking condition. Cells were observed by phase-bright microscopy. Scale bars: $10 \mu \mathrm{m}$. B, Wild-type cells and the $\triangle B c s p o 0 A$ mutant from A were further visualized by transmission electron microscopy for gaining insight into structural details. Scale bars: $1 \mu$ m. C, Heterologous expression of BcspoOA in the $\triangle B$ sspoOA mutant of B. subtilis largely rescued the sporulation deficiency of the mutant. Scale bars: $10 \mu \mathrm{m}$. D, Cell optical density at $600 \mathrm{~nm}$ $\left(\mathrm{OD}_{600}\right)$ of the wild-type strains of both B. subtilis (3610) and B. cereus (AR156), the corresponding spo0A deletion mutants ( $\triangle B$ sspoOA and $\triangle B$ cspoOA), and the $\triangle B$ sspoOA mutant heterologously expressing Bsspo0A. All strains were grown for $36 \mathrm{~h}$ under shaking in DS medium before measurement of cell OD. Error bars represent standard deviations from three independent measurements. E, Colony and pellicle biofilm formation in Luria-Bertani (LB) agar and LB supplemented with $1 \%$ glycerol and $200 \mu \mathrm{M} \mathrm{MnSO}_{4}$ (LBGM) by the wild-type B. subtilis 3610 , the $\triangle B$ sspoOA mutant, the $\triangle B$ sspoOA mutant complemented with $P_{B s p o 0 A}-B s s p o 0 A$ at amyE, and the $\triangle B$ sspoOA mutant heterologously expressing $P_{B s s p o O A}-B c s p o 0 A$ at amyE. Scale bar: 1 cm. 


\section{Genome-wide transcriptional profiling}

in the wild type and $\triangle B c s p o 0 A$ and $\triangle B c s i n I$ mutants revealed potential biofilm and sporulation genes.

Genes involved in biofilm formation and sporulation are largely unknown in $B$. cereus. To identify putative biofilm genes regulated by either Spo0A or SinI, as well as putative sporulation genes regulated by Spo0A in B. cereus AR156, we conducted genome-wide transcriptional profiling in the wildtype strain, the $\triangle B c s p o 0 A$ mutant, and the $\triangle B c \sin I$ mutant. Cells were grown in the biofilm-inducing medium LBGM to $\mathrm{OD}_{600}=2.0$ before harvest (in B. subtilis, Spo0A-controlled sporulation and biofilm genes are known to be induced under this condition) (Shemesh and Chai 2013). Genes exhibiting a twofold or greater difference in expression between the wild type and the $\triangle B$ cspoOA mutant were tentatively designated as BcSpo0A regulon (Supplementary Table S1). In total, 830 genes (or approximately $15 \%$ of the encoded genes in the AR156 genome) showed a differential expression between these two strains by at least twofold, among which 259 genes were expressed lower and 571 genes were expressed higher in the $\triangle$ Bcspo0A mutant (Supplementary Fig. S5). Furthermore, of the 830 genes, 558 exhibited at least an eightfold difference in transcription. Those genes were further grouped based on their annotated functions (Fig. 8A). Because BcSpo0A is a transcription factor and based on characterization of Spo0A binding motif (OA box) in B. subtilis, we speculated that BcSpo0A likely recognizes a similar conserved DNA-binding motif in the regulatory region of its regulon. To verify the presence of such DNA-binding sites of $\mathrm{BcSpo0A}$, the putative promoter sequences (200 bp upstream of the coding sequence) of these 558 genes were retrieved and analyzed with the MEMECHIP program (Machanick and Bailey 2011). Results indicated that 161 of the 558 genes contained a consensus binding sequence $\left(5^{\prime}\right.$-TGAAGAA- $\left.3^{\prime}\right)$ in their corresponding regulatory regions (Fig. 8B). This consensus sequence resembles the Spo0A binding box revealed in B. subtilis ( $5^{\prime}$-TGTCGAA-3') (Molle et al. 2003). Finally, among the 830 genes, 37 have orthologs that have been previously identified as the Spo0A regulon in B. subtilis (Fujita et al. 2005; Molle et al. 2003), which includes spoIIAA, spoOJ, $a b r B, \operatorname{cod} Y, g l p K$, and so on. (Fig. 8C). Interestingly, there are 165 strongly differentially expressed genes that had no orthologs in B. subtilis (E-value $\leq 1 \mathrm{e}-5$ ), indicating that these could be SpoOAregulated cell differentiation genes uniquely present in the B. cereus group (Supplementary Table S2).

When comparing transcription profiling between the wildtype strain and the $\Delta B c \operatorname{cin} I$ mutant, we found differential expression of 955 genes above the twofold threshold. Among them, 315 genes were downregulated and 640 showed an upregulation in the $\Delta B c \operatorname{sinI}$ mutant (Supplementary Table S3). Gene ontology analysis suggested that functions of many of those genes are related to amino acid catabolism and oligopeptide transport (Supplementary Fig. S6).

Given that both $\triangle B c s p o O A$ and $\triangle B c \sin I$ mutants showed a defect in biofilm formation, we speculated that a subset of genes regulated by both Spo0A and SinI might contribute to biofilm formation, especially those downregulated in both mutants. Thus, those downregulated genes were further analyzed. In all, 256 genes $(62.6 \%$ of the total downregulated genes) (Supplementary Table S4) were expressed at a lower level in both mutants when compared with the wild type. These 256 genes were predicted to be involved in approximately 10 different biological processes and were further grouped into seven categories based on the annotated molecular functions. Those annotated functions include hydrolase activities, transferase activities, and ion binding function, many of which are similar to the BaSinR regulon characterized in B. anthracis (Pflughoeft et al. 2011).
In B. subtilis, SinI acts as an antagonist of the biofilm master repressor SinR and the $\operatorname{sinI}$ gene is activated by Spo0A (Bai et al. 1993; Branda et al. 2006; Chai et al. 2011; Newman et al. 2013). Therefore, genes such as the epsA-O and tapA-sipWtas $A$ operons repressed by $\operatorname{SinR}$ are under indirect and positive regulation by both SinI and Spo0A. By taking advantage of the known SinR regulon characterized in both $B$. subtilis and B. anthracis (Chu et al. 2006; Pflughoeft et al. 2011), we predicted that, among the 256 downregulated genes in both the $\triangle B$ cspoOA and $\triangle B$ csinI mutants identified in our transcription profiling, 29 genes might be directly repressed by SinR in B. cereus (Table 2). Of these 29 genes, 18 harbored a consensus 7-bp binding sequence (5'-GTCTTGC-3') in their regulatory regions, similar to the consensus SinR binding sequence characterized in B. subtilis ( $5^{\prime}$-GTTCTCT- $\left.3^{\prime}\right)$. Ten genes have orthologs that were shown to be involved in biofilm formation in B. subtilis, including $y w q D$, galE, guaA, sodA, katA, and so on (Table 2, highlighted in bold). In summary, our results suggest that $\mathrm{BcSpo0A}, \mathrm{BcSinI}$, and $\mathrm{BcSinR}$ in B. cereus may have biological functions in B. cereus similar to their counterparts in $B$. subtilis in regulating cell differentiation and biofilm.

\section{DISCUSSION}

The $B$. cereus group is widely distributed in natural environments. These bacterial species are found to be associated with soils, plants, foods, equipment, or humans as opportunistic pathogens (Bottone 2010; Elhariry 2011; Kotiranta et al. 2000). Survival of these bacteria in versatile ecological niches is highly dependent on their abilities to form biofilms or become dormant spores under various stress conditions (Auger et al. 2009; Elhariry 2011). Previous studies showed that both spores and biofilms of this genus had a higher resistance to heat, antibiotics, UV, and other environmental stresses. Biofilms also serve to increase adhesion to biotic and abiotic surfaces (Ball et al. 2008; Shaheen et al. 2010). B. cereus species form biofilms on solids, at air-liquid interfaces, or as submerged surface-associated biofilms, even though the ability to form biofilms and the morphological robustness of the biofilms vary greatly among the environmental isolates of B. cereus (CaroAstorga et al. 2015; Elhariry 2011; Gao et al. 2015; Peng et al. 2001; Wijman et al. 2007; Yan et al. 2016). On the other hand, structural components of the biofilm matrix and regulatory mechanisms controlling biofilm formation are still very poorly understood in $B$. cereus, in contrast to the well-characterized regulatory networks for biofilm formation in the closely related B. subtilis.

Unlike the previously studied $B$. cereus strains, the biocontrol root-knot nematode strain AR156 cannot form submerged biofilms (Yan et al. 2016). Rather, this bacterium forms floating pellicles in the biofilm-inducing medium LBGM with robust surface features (Fig. 3A). In this study, we explored morphological details of the AR156 pellicle biofilms. The pellicles observed by SEM contained fiber-like structures associated with cell surfaces. These fiber-like structures reached out and formed a web-like network connecting individual cells within the biofilm. To some extent, this resembles the TasA fibers seen in the B. subtilis biofilms (Branda et al. 2001; Romero et al. 2011). These extracellular structures were largely missing in either $\triangle B c s p o O A$ or $\triangle B c \operatorname{sinI}$ mutants (Fig. 3), indicating that SpoOA and SinI may control production of these extracellular components.

A main goal of this study was to characterize the genetic circuit that governs biofilm formation in $B$. cereus AR156. Due to the close relationship between $B$. cereus and $B$. subtilis, we first searched and analyzed orthologs of the major biofilm 
genes of B. subtilis in AR156. Consistent with the findings in previous studies (Caro-Astorga et al. 2015; Gao et al. 2015), there are two TasA-like proteins (CalY1 and CalY2) and the Spo0A-SinI-SinR module in AR156, similar to their orthologs in B. subtilis (Fig. 1). These tasA-like genes have been shown to be important in formation of the submerged biofilms in
$B$. cereus CECT148. On the other hand, no orthologs of the epsA-O operon of $B$. subtilis or the capsular polysaccharide operon of $B$. cereus 14579 was found in the B. cereus AR156 genome. Instead, only an eight-gene cluster with predicted products resembling the proteins encoded in the epsA-O operon was identified in the AR156 genome (Table 1). This eight-gene
A

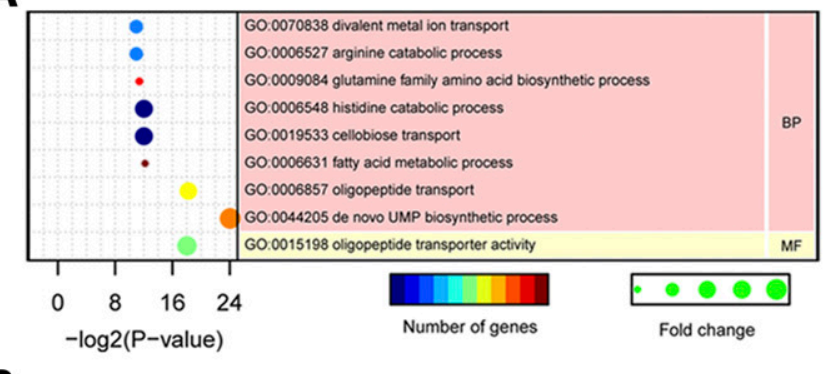

C

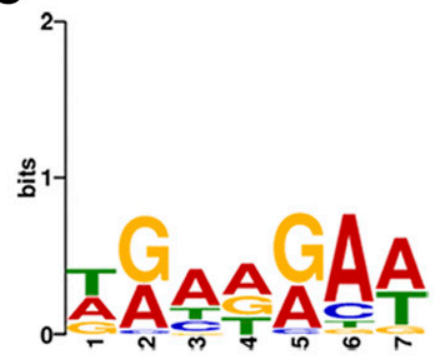

B

\begin{tabular}{|c|c|c|c|c|c|}
\hline GenelD & AR156 & $\triangle \mathrm{BcSpo0A}$ & & $\mathrm{J}_{2} \mathrm{FC}$ & Annotation \\
\hline ORF4170 & 48.2 & 0.01 & 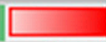 & -12.24 & Stage 0 sporulation protein $\mathrm{A}$ \\
\hline ORF2357 & 1794.7 & 20.8 & $\square$ & -6.43 & Cold shock protein \\
\hline ORF0643 & 388.5 & 8.7 & $\square$ & -5.48 & Arginine permease \\
\hline ORF5239 & 265.0 & 6.3 & $\square$ & -5.40 & Enterotoxin / cell-wall binding protein \\
\hline ORF2487 & 77.9 & 2.6 & 世 & -4.90 & Enoyl-CoA hydratase \\
\hline ORF0813 & 648.9 & 26.9 & 世 & -4.59 & Enterotoxin / cell-wall binding protein \\
\hline ORF4288 & 167.2 & 9.9 & 世 & -4.08 & Membrane-attached cytochrome c550 \\
\hline ORF1149 & 2936.2 & 328.0 & ㄴ. & -3.16 & Ornithine--oxo-acid transaminase \\
\hline ORF4124 & 6915.0 & 846.2 & 口 & -3.03 & MarR family transcriptional regulator \\
\hline ORF4531 & 198.1 & 27.3 & 口 & -2.86 & Hypothetical protein \\
\hline ORF4074 & 127.2 & 17.8 & L & -2.83 & Anti-sigma $\mathrm{F}$ factor antagonist \\
\hline ORF3680 & 724.0 & 183.9 & 4 & -1.98 & Hypothetical protein \\
\hline ORF0042 & 667.4 & 1978.2 & 1.57 & ] & Transcriptional regulator $\mathrm{AbrB}$ \\
\hline ORF1644 & 75.6 & 263.3 & 1.80 & ] & Flagellar MS-ring protein \\
\hline ORF5481 & 144.5 & 549.6 & 1.93 & ] & Stage 0 sporulation protein $\mathrm{J}$ \\
\hline ORF5234 & 417.5 & 1649.1 & 1.98 & ] & $\mathrm{N}$-acetylmuramoyl-L-alanine amidase \\
\hline ORF3826 & 150.4 & 797.3 & 2.41 & ] & Transcriptional repressor CodY \\
\hline ORF1634 & 16.8 & 96.3 & 2.52 & ] & Hypothetical protein \\
\hline ORF0001 & 15.1 & 95.8 & 2.67 & ] & Replication initiation protein \\
\hline ORF0170 & 18.3 & 130.6 & 2.83 & ] & KinB activation protein \\
\hline ORF4380 & 343.0 & 2491.8 & 2.86 & ] & Hypothetical protein \\
\hline ORF4653 & 10.8 & 79.9 & 2.89 & $\square$ & GAF domain-containing protein \\
\hline ORF2292 & 20.9 & 205.4 & 3.30 & 0 & 3-hydroxyisobutyryl-CoA hydrolase \\
\hline ORF5187 & 16.6 & 164.5 & 3.31 & ] & Cytochrome c-551 \\
\hline ORF4298 & 13.3 & 134.0 & 3.34 & $\square$ & Cytidine deaminase \\
\hline ORF0397 & 8.5 & 106.0 & 3.64 & $\square$ & Cytoplasmic protein \\
\hline ORF1713 & 7.7 & 113.5 & 3.88 & $\square$ & Hypothetical protein \\
\hline ORF1035 & 202.8 & 3628.8 & 4.16 & $\square$ & Glycerol kinase \\
\hline ORF0593 & 241.5 & 4477.9 & 4.21 & $\square$ & Alanine permease \\
\hline ORF1823 & 14.4 & 513.2 & 5.15 & $\square$ & Cytidine deaminase \\
\hline ORF5490 & 116.8 & 4993.9 & 5.42 & $\square$ & 50 S ribosomal protein L34 \\
\hline ORF5200 & 0.43 & 47.2 & 6.77 & $\square$ & LytR family transcriptional regulator \\
\hline ORF0428 & 0.01 & 19.0 & 10.89 & $\square$ & $A B C$ protein uup \\
\hline ORF1594 & 0.01 & 25.6 & 11.32 & $\square$ & Isochorismatase \\
\hline ORF5250 & 0.01 & 29.6 & 11.53 & $\square$ & Competence transcription factor \\
\hline ORF3983 & 0.01 & 39.7 & 11.96 & $\square$ & CBS domain-containing protein \\
\hline ORF0681 & 0.01 & 40.2 & 11.97 & $\square$ & Hypothetical protein \\
\hline ORF3898 & 0.01 & 251.5 & 14.62 & & Hypothetical protein \\
\hline
\end{tabular}

Fig. 8. Genome-wide transcriptome analyses of the BcSpo0A regulon in Bacillus cereus AR156. A, Gene ontology analyses predicted genes regulated by BcSpo0A in AR156 from transcriptional profiling experiments. B, Consensus DNA-binding motif of BcSpo0A predicted based on analyses of the differentially expressed genes in $\triangle B$ cspoOA using the MEME-CHIP program. C, Expression patterns of 37 genes under the Spo0A control in both B. cereus and B. subtilis. 
cluster is highly conserved in $B$. cereus yet its function is completely unknown. Unfortunately, results from the transcriptome profiling indicate that the expression of these eight genes was not significantly altered in either the $\triangle B$ cspoOA or the $\Delta B c \sin I$ mutant under the tested conditions. However, it is still possible that this putative eight-gene EPS cluster plays a role in pellicle biofilm development, although expression of the EPS gene cluster is not controlled by either Spo0A or SinI in AR156. In previous studies, a 21-gene cluster with predicted products bearing many of the hallmarks of EPS biosynthetic machinery was identified in both B. cereus 905 and ATCC14579 (Gao et al. 2016). However, the mutant with a deletion of this gene cluster in B. cereus 905 was not affected in biofilm formation. Thus far, no published report has suggested an important role of any secreted polysaccharide in biofilm formation in B. cereus.

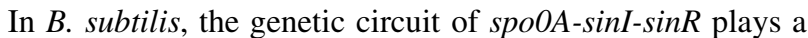
central role in regulating biofilm formation (Branda et al. 2001; Chu et al. 2006; Kearns et al. 2005). Our evidence, based on mutagenesis, heterologous expression of gene orthologs, and transcription profiling, suggests that the similar genetic circuit (Bcspo0A-BcsinI-BcsinR) also plays a central role in biofilm formation and cell differentiation in B. cereus AR156. Those homolog proteins in both $B$. subtilis and $B$. cereus are functionally very similar to each other. For instance, we showed that $\mathrm{BcSinI}$ may cross-interact with BsSinR, and that BcSinR, when heterologously produced in $B$. subtilis, was able to regulate the biofilm genes controlled by BsSinR. Obviously, one should still expect major differences in the control mechanism for biofilm formation between B. subtilis and B. cereus. For example, some of the important regulatory proteins such as YwcC, SlrA, and SlrR in B. subtilis have no orthologs in the B. cereus strains (Chai et al. 2009, 2010).

Hundreds of genes putatively regulated by BcSpoOA and BcSinI in B. cereus AR156 were first revealed in this study based on the transcriptome analyses. In addition, based on the knowledge of biofilm regulation in other Bacillus spp., 29 genes under the regulation of BcSpo0A-SinI-SinR were speculated to be under the direct control of SinR in AR156 (Table 2). Interestingly, some of the 29 genes showing differential expression between the wild type and the $\triangle B$ cspoOA and $\Delta B c \sin I$ mutants do not have orthologs in B. subtilis 3610 . This indicated that some of the BcSpo0A-SinI-SinR-controlled genes in $B$. cereus were unique to the $B$. cereus group. These genes could provide unique features to the $B$. cereus biofilms.

The Caenorhabditis elegans-bacteria interaction model has been widely used to identify factors in both the bacteria and the host that are involved in biofilm-mediated interactions between bacteria and invertebrates (Begun et al. 2007; Darby et al. 2002; DePas et al. 2014; Drace and Darby 2008; Joshua et al. 2003; Tan et al. 1999). Yersinia pseudotuberculosis, Y. pestis, and Xenorhabdus nematophila were shown to kill $C$. elegans by forming biofilms around the head of the nematodes, which prevented food intake and subsequently caused death of C. elegans due to starvation (Darby et al. 2002; Drace and Darby 2008; Joshua et al. 2003). Mutations in the EPS operon hmsHFRS significantly reduced biofilm formation and colonization of the above three bacterial species, and attenuated the pathogenicity of the bacteria against $C$. elegans (Drace and Darby 2008). Streptococcus epidermidis and Staphylococcus aureus are also pathogenic bacteria and form biofilms during the infection of $C$. elegans (Begun et al. 2007). The mutants of the icaADBC operon encoding a biofilm-associated polysaccharide adhesin (PIA) lost the nematicidal activity, which led to decreased accumulation of bacteria in the $C$. elegans intestine (Begun et al. 2007). On the other hand, overexpression of the icaADBC operon in $S$. aureus increased virulence toward nematodes. Furthermore, biofilm formation is critical for bacterial survival inside the gut of nematodes. PIA-producing Streptococcus epidermidis has a significant survival advantage

Table 2. Predicted BcSinR-regulated biofilm genes in Bacillus cereus AR156a

\begin{tabular}{|c|c|c|c|c|c|}
\hline Gene ID & $\log _{2}(\Delta B C \operatorname{Cspo0A} / W T)$ & $\log _{2}(\Delta \mathrm{BcSin} / \mathrm{WT})$ & Annotation & Gene & Note $^{\text {b }}$ \\
\hline ORF0296 & -1.63 & -1.67 & GMP synthase & guaA & Yan et al. 2016 \\
\hline ORF0707 & -5.11 & -5.96 & Ferrous iron transport protein & NA & Yan et al. 2016 \\
\hline ORF0708 & -3.89 & -3.84 & Ferrous iron transport protein & NA & Yan et al. 2016 \\
\hline ORF1047 & -4.96 & -3.36 & Transcriptional regulator $\mathrm{Hpr}$ & $h p r$ & Madec et al. 2002 \\
\hline ORF1155 & -2.02 & -2.97 & Catalase & katA & Ostress \\
\hline ORF5445 & -4.03 & -3.41 & Superoxide dismutase (Mn) & $\operatorname{sod} A$ & Ostress \\
\hline ORF1638 & -2.13 & -3.15 & Flagellar capping protein & filD & Chai et al. 2010 \\
\hline ORF1651 & -5.98 & -5.21 & Flagellar hook protein FlgE & filG & Chai et al. 2010 \\
\hline ORF5263 & -4.11 & -4.54 & UDP-glucose 4-epimerase & galE & Chai et al. 2012 \\
\hline ORF0344 & -2.89 & -3.50 & Pyrroline-5-carboxylate dehydrogenase & $y c g N$ & Chu et al. 2006 \\
\hline ORF0666 & -3.02 & -4.43 & Immune inhibitor A precursor & $\operatorname{inh} A$ & Pflughoeft et al. 2011 \\
\hline ORF3882 & -6.27 & -5.71 & Orotatephosphoribosyltransferase & pyrE & Yan et al. 2016 \\
\hline ORF3883 & -6.49 & -6.39 & Orotidine $5^{\prime}$-phosphate decarboxylase & pyrF & Yan et al. 2016 \\
\hline ORF3884 & -6.01 & -5.71 & Dihydroorotate dehydrogenase $1 \mathrm{~B}$ & pyrD & Yan et al. 2016 \\
\hline ORF3885 & -7.21 & -6.66 & Dihydroorotate dehydrogenase & pyrK & Yan et al. 2016 \\
\hline ORF3886 & -7.07 & -7.33 & Carbamoyl phosphate synthase & $\operatorname{carB}$ & Yan et al. 2016 \\
\hline ORF3887 & -8.48 & -8.14 & Carbamoyl phosphate synthase & pyrAA & Yan et al. 2016 \\
\hline ORF3888 & -8.53 & -7.30 & Dihydroorotase & pyrC & Yan et al. 2016 \\
\hline ORF3889 & -6.09 & -6.02 & Aspartatecarbamoyltransferase & pyrB & Yan et al. 2016 \\
\hline ORF3942 & -3.80 & -4.40 & Cytochrome c oxidase polypeptide III & catE & OR \\
\hline ORF3943 & -5.87 & -6.30 & Cytochrome c oxidase polypeptide I & catD & OR \\
\hline ORF3944 & -4.00 & -3.96 & Cytochrome c oxidase polypeptide II & catC & OR \\
\hline ORF3945 & -2.97 & -2.68 & Protoheme IX farnesyltransferase & catB & OR \\
\hline ORF4126 & -7.33 & -6.66 & Ornithinecarbamoyltransferase & $\arg F$ & $\mathrm{AM}$ \\
\hline ORF4148 & -8.79 & -5.92 & Arginine ATP-binding protein & $\operatorname{artR}$ & $\mathrm{AM}$ \\
\hline ORF4149 & -10.67 & -7.10 & Arginine $\mathrm{ABC}$ transporter permease & $\operatorname{art} Q$ & $\mathrm{AM}$ \\
\hline ORF4150 & -11.85 & -8.20 & Arginine-binding protein & $\operatorname{art} \widetilde{P}$ & $\mathrm{AM}$ \\
\hline ORF4629 & -6.06 & -5.75 & Argininosuccinatelyase & $\operatorname{argH}$ & AsucM \\
\hline ORF4630 & -8.32 & -6.43 & Argininosuccinate synthase & $\arg G$ & AsucM \\
\hline
\end{tabular}

${ }^{\mathrm{a}} \mathrm{WT}=$ wild type and $\mathrm{NA}=$ not available.

${ }^{\mathrm{b}}$ Ostress = oxidative stress response, $\mathrm{OR}=$ oxidative respiration, $\mathrm{AM}=$ arginine metabolism, and AsucM = argininosuccinate metabolism. 
over the ica-deficient mutant within the intestinal tract of C. elegans (Begun et al. 2007). Biofilm matrix components curli and cellulose could protect $E$. coli against killing by C. elegans. Matrix-encased bacteria at the air-biofilm interface exhibited a 40-fold increase in survival after $C$. elegans killing compared with the non-matrix-encased cells (DePas et al. 2014). Consistent with the above studies, our data in the present study suggested that biofilm formation by the biocontrol agent $B$. cereus AR156 was also very important for killing against the plant-parasitic nematode $M$. incognita. Colonization ability, mortality against $\mathrm{J} 2$ of $M$. incognita, and biocontrol efficacy were all significantly declined in the treatments by the biofilmdefective mutants compared with the wild-type strain.

It is worth noting that the killing activity was not completely lost in the $\triangle B$ cspoOA and $\triangle B c \sin I$ mutants of AR156 (Fig. 2A), indicating that a biofilm-independent mechanism may also function in nematode killing. In $Y$. pestis KIM5, four proteins-a protease OmpT, a metalloprotease Y3857, an adhesion protein $\mathrm{YapH}$, and a putative exported protein Y0340 - were found to be associated with virulence on C. elegans in an independent process on biofilms (Styer et al. 2005). Hemolysin II, immune inhibitor A, and enhancin have been suggested as virulence factors toward the larvae of Lepidoptera and nematodes in B. thuringiensis and Vibrio cholerae (Cinar et al. 2010; Wang et al. 2016). Bioinformatics analyses indicated that there were several genes encoding the above factors in the genome of AR156. Genes encoding these factors were significantly downregulated in both the $\triangle B$ cspoOA and $\Delta B c \sin I$ mutants. This indicates that those virulence-related genes may also be regulated by the $\operatorname{spo} 0 \mathrm{~A} / \sin R / \sin I$ circuitry and contribute to nematode killing and biocontrol efficacy in addition to biofilm formation. Furthermore, the $\triangle B c s p o O A$ and $\Delta B c \sin I$ mutants have a similar biofilm defect but differ significantly in mortality rate of the nematodes. This reinforces the idea that, in addition of biofilm formation, other unknown factors controlled by Spo0A also contribute to the nematicidal activity by AR156.

\section{MATERIALS AND METHODS}

\section{Strains and media.}

B. subtilis wild-type strain 3610, B. cereus wild-type strain AR156, and other derivatives were routinely grown in LB broth ( $10 \mathrm{~g}$ of tryptone, $5 \mathrm{~g}$ of yeast extract, and $5 \mathrm{~g}$ of $\mathrm{NaCl}$ per liter of broth) at $37^{\circ} \mathrm{C}$. Approximately $1.5 \%$ agar was included when making solid agar medium. LBGM medium was used for assays of biofilm formation. Sporulation assays were performed in DS medium (Schaeffer et al. 1965). Antibiotics were added at the following concentrations: tetracycline at $10 \mu \mathrm{g} \mathrm{ml}^{-1}$, spectinomycin at $100 \mu \mathrm{g} \mathrm{ml}^{-1}$, kanamycin at $20 \mu \mathrm{g} \mathrm{ml}^{-1}$, chloramphenicol at $5 \mu \mathrm{g} \mathrm{ml}^{-1}$, and erythromycin at $1 \mu \mathrm{g} \mathrm{ml}^{-1}$. Chemicals were purchased from Sigma. Restriction enzymes and other enzymes for molecular cloning were obtained from New England Biolabs. All primers were ordered from IDT DNA technology. DNA sequencing was performed at Genewiz. All strains used in this study are described in Supplementary Table S5. All primers used in this study are listed in Supplementary Table S6.

\section{Strain construction.}

The BcspoOA mutant strain was constructed by the doublecrossover recombination following a procedure described in a previous study (Gao et al. 2015). To explain briefly, homologous regions of the upstream and downstream regions of the Bcspo0A gene were amplified from $B$. cereus AR156 genome using the primers spo0A-Up-F/R and spo0A-Down-F/R, respectively. These two DNA fragments were digested with

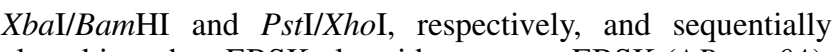
cloned into the pEBSK plasmid to create pEBSK $(\triangle B$ cspoOA). The long flanking DNA fragment (designated as Up-KmDown) was amplified by polymerase chain reaction (PCR) using pEBSK $(\triangle B c s p o 0 A)$ as the template and primers spo0A-F and spo0A-R. The fragment was then digested with BglII and MluI, and cloned into a temperature-sensitive E. coli and Bacillus shuttle vector pMAD (Arnaud et al. 2004) to generate pMAD $(\triangle B$ cspoOA). The pMAD $(\triangle B$ cspoOA) plasmid was mobilized into $B$. cereus AR156 by electroporation. Transformants were obtained and screened as described in the previously published protocol (Gao et al. 2015). All mutants were subsequently confirmed by PCR amplification and DNA sequencing to verify the presence of the BcspoOA::Km allele on the chromosome. Replacement of BcsinI in the B. cereus AR156 chromosome with the kanamycin resistance cassette was carried out similarly to that of $\triangle B c s p o 0 A:: \mathrm{Km}$, except that different primers were used to amplify the upstream and downstream regions of the BcsinI gene.

The heterologous expression strains were generated as follows. For heterogonous expression of the $B c \sin I$ gene at the ectopic amyE locus in the $\triangle B$ ssinI mutant of B. subtilis, the $B$ csinI gene was amplified by PCR using AR156 genome DNA as the template and primers BcsinI-F and BcsinI-R. The PCR products were digested with NotI and SacII and inserted into the pYC151 plasmid (Chai et al. 2010), resulting in the recombinant plasmid pCY560. The pCY560 plasmid contains the $g f p-B c \sin I$ fusion under the control of a constitutively expressed promoter hyperspank. To express the $B c \sin R$ at the amy $E$ locus in the $\Delta B \operatorname{ssin} R$ mutant of $B$. subtilis, the promoter and coding region of $B c \sin R$ was amplified from $B$. cereus AR156 using the primers BcsinR-F and BcsinR. The PCR fragment was digested with EcoRI and BamHI and inserted into the pDG1730 plasmid (Britton et al. 2002), resulting in the recombinant plasmid pCY558. To express the BcspoOA gene under the BsspoOA promoter at the amyE locus in the $\triangle B$ sspoOA mutant of $B$. subtilis, the promoter region of BsspoOA was fused with the $B$ cspo0A coding region using the overlapping PCR, and a fused fragment was inserted into the pDG1730 plasmid to generate the recombinant plasmid pCY559. All of the above recombinant plasmids were then introduced into PY79 by transformation (Gryczan et al. 1978). A double-crossover recombination at the amyE locus on the chromosome of PY79 was confirmed. The amyE fragments were then introduced into different strain backgrounds by SSP1 phage-mediated transduction.

\section{Analysis of biofilm formation and pellicle biomass.}

To analyze pellicle biofilm formation, cells were first grown in $3 \mathrm{ml}$ of $\mathrm{LB}$ broth to $\mathrm{OD}_{600}=1$. Culture $(3 \mu \mathrm{l})$ was added to $3 \mathrm{ml}$ of LBGM medium in 12-well polyvinyl plates (VWR). The plates were incubated statically at $30^{\circ} \mathrm{C}$ for 24 to $48 \mathrm{~h}$. For colony biofilm formation, $2 \mu \mathrm{l}$ of the cells was spotted onto LBGM medium solidified with $1.5 \%$ agar. Plates were incubated at $30^{\circ} \mathrm{C}$ for 48 to $72 \mathrm{~h}$ prior to analysis. Images were taken by a Nikon CoolPix camera. The biomass of pellicle was analyzed following in a protocol that we previously described (Yan et al. 2016).

\section{Assays of the swarm and sporulation efficiency.}

For the swarm assay, a 5- $\mu$ l cell suspension $\left(\mathrm{OD}_{600}=0.5\right)$ of wild-type AR156 or mutants was inoculated on the center of $0.7 \% \mathrm{LB}$ agar plates and incubated at $30^{\circ} \mathrm{C}$ for $12 \mathrm{~h}$. Six plates were used for each individual strain. The experiments were repeated three times.

Heat-killing experiments were performed to compare the sporulation efficiency among the wild type, the mutants, and 
the complementation strains of both B. cereus and B. subtilis. After growing in DS medium for $24 \mathrm{~h}$ (for B. subtilis) or $36 \mathrm{~h}$ (for B. cereus), cells were serially diluted and plated on LB agar media to determine the number of total cells by CFU counting. Diluted samples were then incubated in the water bath at $80^{\circ} \mathrm{C}$ for $20 \mathrm{~min}$, briefly cooled, and plated on the LB agar media again. The next day, CFU were counted for cells before and after heat kill. Sporulation efficiency was calculated as the percentage of heat-resistant spores versus total cells. The spores generated in different strains were visualized by Leica AF6000 Modular microsystems.

\section{Microscopic analysis.}

Pellicle biofilms were visualized by SEM. Pellicles were harvested after 3 days of incubation in LBGM medium and fixed in a mixture of $2 \%$ paraformaldehyde and $2 \%$ glutaral-

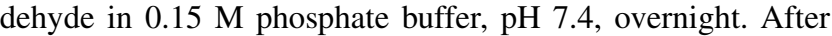
fixation, tissues were rinsed three times (15 min each) with $0.1 \mathrm{M}$ phosphate-buffered saline and dehydrated in graded ethanol solutions before critical point drying with $\mathrm{CO}_{2}$. Examination of samples was performed in a Hitachi S-4700 field emission scanning electron microscope, and secondary electron images were collected as TIFF files. The structure of cells or spores of mutants after incubation in DS medium was examined by a transmission electronic microscope.

\section{Transcriptional profiling.}

B. cereus wild-type strain AR156, $\triangle B$ csinI, and $\triangle B$ cspoOA were grown in LBGM to $\mathrm{OD}_{600}=2.0$ and harvested for total RNA extraction. After the total RNA extraction and DNase I treatment, magnetic beads with oligo (dT) were used to remove ribosomal RNA from the total RNA. Samples were mixed with the fragmentation buffer, and the mRNA was fragmented into short fragments. The cDNA was then synthesized using the mRNA fragments as templates. Short fragments were purified and resolved in elution buffer for end reparation and single nucleotide A (adenine) addition. After that, the short fragments were linked with adapters. The modified cDNA library was sequenced using Illumina HiSeq 2000. Differential expression statistics reflecting both effective size (fold-change) and statistical significance $(P$ value adjusted based on the method of Benjamini and Hochberg) were calculated using DESeq. Duplicate reads were excluded from the analyses. Differentially expressed genes were identified based on a minimum fold-change and maximum $P$ value. The consensus DNA-binding sequences of $\mathrm{BcSpoOA}$ and $\mathrm{BcSinR}$ were analyzed by the MEME-CHIP program (Machanick and Bailey 2011).

\section{Nematicidal activity against tomato root-knot nematode disease.}

To evaluate the nematicidal activity of $B$. cereus AR156 and its mutants against $M$. incognita in vitro, the $\mathrm{J} 2$ were cocultured with different strains for an indicated period of time, and the mortality rate of the worms was then calculated. Briefly, the Bacillus strains were grown in LB broth at $28^{\circ} \mathrm{C}$ for $24 \mathrm{~h}$ with shaking at $200 \mathrm{rpm}$, and cells were harvested and resuspended with sterilized water. The concentration of cell suspension was adjusted to $1 \times 10^{8} \mathrm{CFU} / \mathrm{ml}$ prior to use. J2 were prepared following Fusali's method (Fudali et al. 2013) and the number of $\mathrm{J} 2$ was adjusted to $4,000 \mathrm{~J} 2 / \mathrm{ml}$. Bacterial cell suspension $(250 \mu \mathrm{l})$ and $\mathrm{J} 2(250 \mu \mathrm{l})$ were then mixed well in a $1.5-\mathrm{ml}$ Eppendorf tube and incubated at $28^{\circ} \mathrm{C}$ for $24 \mathrm{~h}$. After incubation, the number of live and dead worms in each treatment was counted by the stereomicroscope. The mortality rate was calculated according to the following formula: mortality rate $=$ (number of dead worms/number of total worms) $\times 100 \%$.
To quantify the number of bacterial cells on the worm body surface in coculture treatment, worms in each treatment were picked up with a needle after $24 \mathrm{~h}$ of incubation, soaked in sterile water, and vortexed for $5 \mathrm{~min}$. Serial dilutions of a cell suspension were spread on LB medium supplemented with appropriate antibiotics. The number of bacterial cells per worm was analyzed by plating and CFU counting. Experiments were repeated three times.

\section{Biocontrol efficacy \\ against tomato root-knot nematode disease.}

Biocontrol efficacy of $B$. cereus AR156 and derivatives against $M$. incognita was conducted to control tomato root-knot nematode diseases under greenhouse conditions following the protocol that we published previously (Wei et al. 2010). Briefly, tomato seed ('Shanghai Cooperation 903', provided by the Chinese Academy of Agricultural Sciences) were surface sterilized, planted in sterilized soil in pots, and maintained in a greenhouse at $26^{\circ} \mathrm{C}$ for 4 weeks. Seedlings were transplanted to new pots $(10 \mathrm{~cm}$ in diameter) containing fertilizer and then maintained at $26^{\circ} \mathrm{C}$ in a greenhouse with relative humidity of $40 \%$ and a photoperiod of 12 and $12 \mathrm{~h}$ for 2 days. The individual seedlings in each pot were first inoculated with AR156 or mutants by carefully pouring $40 \mathrm{ml}$ of bacterial suspension $\left(10^{9} \mathrm{CFU} / \mathrm{ml}\right)$ into the rhizosphere of each plant. The inoculated pots were maintained under the same conditions as described above for 2 more days. Each pot was inoculated with $10 \mathrm{ml}$ of a nematode suspension containing 600 freshly hatched J2. As a control, an equal amount of sterilized water instead of an antagonist suspension was added to the pots. Each treatment consisted of three replicates and each replicate had 24 plants. All pots were arranged in a randomized block design. The number of galls per root system was counted 56 days after the inoculation with nematodes. The gall indices were confirmed by using the 0-to-11 scale of Bridge and Page (1980) and biocontrol efficacy were calculated as described by Xue et al. (2009). The survival of the wild-type strain and the mutants in the rhizosphere soil was monitored over a period of time by following a previously published protocol (Chen et al. 2013).

\section{ACKNOWLEDGMENTS}

We thank H. Liu (Northwest A\&F University) for bioinformatics analyses and K. Gozzi (Massachusetts Institute of Technology) for language editing. The research was supported by the National Natural Science Foundation of China (31301707) and by the Fundamental Research Funds for the Central Universities (2014QNA6018) to Y. Chen, a startup grant from Northeastern University to Y. Chai, and the National Natural Science Foundation of China (31471812) to J. Guo.

\section{LITERATURE CITED}

Ali, N. I., Siddiqui, I. A., Shaukat, S. S., and Zaki, M. J. 2002. Nematicidal activity of some strains of Pseudomonas spp. Soil Biol. Biochem. 34: 1051-1058.

Andersen, J. B., Koch, B., Nielsen, T. H., Sorensen, D., Hansen, M., Nybroe, O., Christophersen, C., Sorensen, J., Molin, S., and Givskov, M. 2003. Surface motility in Pseudomonas sp. DSS73 is required for efficient biological containment of the root-pathogenic microfungi Rhizoctonia solani and Pythium ultimum. Microbiology 149:37-46.

Arnaud, M., Chastanet, A., and Debarbouille, M. 2004. New vector for efficient allelic replacement in naturally nontransformable, low-GCcontent, gram-positive bacteria. Appl. Environ. Microbiol. 70:68876891.

Atkinson, S., Goldstone, R. J., Joshua, G. W. P., Chang, C. Y., Patrick, H. L., Camara, M., Wren, B. W., and Williams, P. 2011. Biofilm development on Caenorhabditis elegans by Yersinia is facilitated by quorum sensing-dependent repression of type III secretion. PLoS Pathog. 7:e1001250.

Auger, S., Ramarao, N., Faille, C., Fouet, A., Aymerich, S., and Gohar, M. 2009. Biofilm formation and cell surface properties among pathogenic 
and nonpathogenic strains of the Bacillus cereus group. Appl. Environ. Microbiol. 75:6616-6618.

Bai, U., Mandic-Mulec, I., and Smith, I. 1993. SinI modulates the activity of SinR, a developmental switch protein of Bacillus subtilis, by proteinprotein interaction. Genes Dev. 7:139-148.

Bais, H. P., Fall, R., and Vivanco, J. M. 2004. Biocontrol of Bacillus subtilis against infection of Arabidopsis roots by Pseudomonas syringae is facilitated by biofilm formation and surfactin production. Plant Physiol. 134:307-319.

Ball, D. A., Taylor, R., Todd, S. J., Redmond, C., Couture-Tosi, E., Sylvestre, P., Moir, A., and Bullough, P. A. 2008. Structure of the exosporium and sublayers of spores of the Bacillus cereus family revealed by electron crystallography. Mol. Microbiol. 68:947-958.

Begun, J., Gaiani, J. M., Rohde, H., Mack, D., Calderwood, S. B., Ausubel, F. M., and Sifri, C. D. 2007. Staphylococcal biofilm exopolysaccharide protects against Caenorhabditis elegans immune defenses. PLoS Pathog. 3:e57.

Bianciotto, V., Andreotti, S., Balestrini, R., Bonfante, P., and Perotto, S. 2001. Mucoid mutants of the biocontrol strain Pseudomonas fluorescens CHA0 show increased ability in biofilm formation on mycorrhizal and nonmycorrhizal carrot roots. Mol. Plant-Microbe Interact. 14:255-260.

Bottone, E. J. 2010. Bacillus cereus, a volatile human pathogen. Clin. Microbiol. Rev. 23:382-398.

Branda, S. S., Chu, F., Kearns, D. B., Losick, R., and Kolter, R. 2006. A major protein component of the Bacillus subtilis biofilm matrix. Mol. Microbiol. 59:1229-1238.

Branda, S. S., Gonzalez-Pastor, J. E., Ben-Yehuda, S., Losick, R., and Kolter, R. 2001. Fruiting body formation by Bacillus subtilis. Proc. Natl. Acad. Sci. U.S.A. 98:11621-11626.

Branda, S. S., Vik, S., Friedman, L., and Kolter, R. 2005. Biofilms: The matrix revisited. Trends Microbiol. 13:20-26.

Bridge, J., and Page, S. L. J. 1980. Estimation of root-knot nematode infestation levels on roots using a rating chart. Trop. Pest Manage. 26: 296-298.

Britton, R. A., Eichenberger, P., Gonzalez-Pastor, J. E., Fawcett, P., Monson, R., Losick, R., and Grossman, A. D. 2002. Genome-wide analysis of the stationary-phase sigma factor (sigma-H) regulon of Bacillus subtilis. J. Bacteriol. 184:4881-4890.

Caro-Astorga, J., Perez-Garcia, A., de Vicente, A., and Romero, D. 2015. A genomic region involved in the formation of adhesin fibers in Bacillus cereus biofilms. Front. Microbiol. 5:745.

Chai, Y., Beauregard, P. B., Vlamakis, H., Losick, R., and Kolter, R. 2012. Galactose metabolism plays a crucial role in biofilm formation by Bacillus subtilis. MBio 3:e00184-00112.

Chai, Y., Kolter, R., and Losick, R. 2009. Paralogous antirepressors acting on the master regulator for biofilm formation in Bacillus subtilis. Mol. Microbiol. 74:876-887.

Chai, Y., Norman, T., Kolter, R., and Losick, R. 2010. An epigenetic switch governing daughter cell separation in Bacillus subtilis. Genes Dev. 24: 754-765.

Chai, Y., Norman, T., Kolter, R., and Losick, R. 2011. Evidence that metabolism and chromosome copy number control mutually exclusive cell fates in Bacillus subtilis. EMBO J. 30:1402-1413.

Chen, Y., Cao, S., Chai, Y., Clardy, J., Kolter, R., Guo, J. H., and Losick, R. 2012. A Bacillus subtilis sensor kinase involved in triggering biofilm formation on the roots of tomato plants. Mol. Microbiol. 85:418-430.

Chen, Y., Yan, F., Chai, Y., Liu, H., Kolter, R., Losick, R., and Guo, J. H 2013. Biocontrol of tomato wilt disease by Bacillus subtilis isolates from natural environments depends on conserved genes mediating biofilm formation. Environ. Microbiol. 15:848-864.

Chu, F., Kearns, D. B., Branda, S. S., Kolter, R., and Losick, R. 2006. Targets of the master regulator of biofilm formation in Bacillus subtilis. Mol. Microbiol. 59:1216-1228.

Chu, F., Kearns, D. B., McLoon, A., Chai, Y., Kolter, R., and Losick, R 2008. A novel regulatory protein governing biofilm formation in Bacillus subtilis. Mol. Microbiol. 68:1117-1127.

Cinar, H. N., Kothary, M., Datta, A. R., Tall, B. D., Sprando, R., Bilecen, K., Yildiz, F., and McCardell, B. 2010. Vibrio cholerae hemolysin is required for lethality, developmental delay, and intestinal vacuolation in Caenorhabditis elegans. PLoS One 5:e11558.

Colledge, V. L., Fogg, M. J., Levdikov, V. M., Leech, A., Dodson, E. J., and Wilkinson, A. J. 2011. Structure and organisation of SinR, the master regulator of biofilm formation in Bacillus subtilis. J. Mol. Biol. 411: 597-613.

Darby, C., Hsu, J. W., Ghori, N., and Falkow, S. 2002. Caenorhabditis elegans: Plague bacteria biofilm blocks food intake. Nature 417:243-244.

Davey, M. E., and O’Toole, G. A. 2000. Microbial biofilms: From ecology to molecular genetics. Microbiol. Mol. Biol. Rev. 64:847-867.
DePas, W. H., Syed, A. K., Sifuentes, M., Lee, J. S., Warshaw, D., Saggar, V., Csankovszki, G., Boles, B. R., and Chapman, M. R. 2014. Biofilm formation protects Escherichia coli against killing by Caenorhabditis elegans and Myxococcus xanthus. Appl. Environ. Microbiol. 80: 7079-7087

Drace, K., and Darby, C. 2008. The hmsHFRS operon of Xenorhabdus nematophila is required for biofilm attachment to Caenorhabditis elegans. Appl. Environ. Microbiol. 74:4509-4515.

Elhariry, H. M. 2011. Attachment strength and biofilm forming ability of Bacillus cereus on green-leafy vegetables: Cabbage and lettuce. Food Microbiol. 28:1266-1274.

Fudali, S. L., Wang, C., and Williamson, V. M. 2013. Ethylene signaling pathway modulates attractiveness of host roots to the root-knot nematode Meloidogyne hapla. Mol. Plant-Microbe Interact. 26:75-86.

Fujita, M., Gonzalez-Pastor, J. E., and Losick, R. 2005. High- and lowthreshold genes in the Spo0A regulon of Bacillus subtilis. J. Bacteriol. 187:1357-1368

Gao, S. F., Wu, H. J., Yu, X. F., Qian, L. M., and Gao, X. W. 2016. Swarming motility plays the major role in migration during tomato root colonization by Bacillus subtilis SWR01. Biol. Control 98:11-17.

Gao, T., Foulston, L., Chai, Y., Wang, Q., and Losick, R. 2015. Alternative modes of biofilm formation by plant-associated Bacillus cereus. MicrobiologyOpen 4:452-464.

Giannakou, I. O., Sidiropoulos, A., and Prophetou-Athanasiadou, D. 2002. Chemical alternatives to methyl bromide for the control of root-knot nematodes in greenhouses. Pest Manage. Sci. 58:290-296.

Grossman, A. D. 1991. Integration of developmental signals and the initiation of sporulation in Bacillus subtilis. Cell 65:5-8.

Gryczan, T. J., Contente, S., and Dubnau, D. 1978. Characterization of Staphylococcus aureus plasmids introduced by transformation into Bacillus subtilis. J. Bacteriol. 134:318-329.

Haggag, W. M., and Timmusk, S. 2008. Colonization of peanut roots by biofilm-forming Paenibacillus polymyxa initiates biocontrol against crown rot disease. J. Appl. Microbiol. 104:961-969.

Hobley, L., Ostrowski, A., Rao, F. V., Bromley, K. M., Porter, M., Prescott, A. R., MacPhee, C. E., van Aalten, D. M. F., and Stanley-Wall, N. R. 2015 Correction for Hobley et al., BslA is a self-assembling bacterial hydrophobin that coats the Bacillus subtilis biofilm. (First published 2013, Proc. Natl. Acad. Sci. U.S.A. 110:13600-13605.) Proc. Natl. Acad. Sci. U.S.A. 112:E5371E5375.

Hoch, J. A. 1993. spo0 Genes, the phosphorelay, and the initiation of sporulation. Pages 747-755 in: Bacillus subtilis and Other Gram-Positive Bacteria. American Society of Microbiology, Sterling, VA, U.S.A.

Huang, W. K., Sun, J. H., Cui, J. K., Wang, G. F., Kong, L. A., Peng, H., Chen, S. L., and Peng, D. L. 2014. Efficacy evaluation of fungus Syncephalastrum racemosum and nematicide avermectin against the root-knot nematode Meloidogyne incognita on cucumber. PLoS One 9:e89717.

Hunt, D. J., and Handoo, Z. A. 2009. Taxonomy, identification and principal species. Pages 55-97 in: Root-knot Nematodes. R. N. Perry, M. Moens, and J. L. Starr, eds. CABI, Wallingford, UK.

Ivanova, N., Sorokin, A., Anderson, I., Galleron, N., Candelon, B., Kapatral, V., Bhattacharyya, A., Reznik, G., Mikhailova, N., Lapidus, A., Chu, L., Mazur, M., Goltsman, E., Larsen, N., D’Souza, M., Walunas, T., Grechkin, Y., Pusch, G., Haselkorn, R., Fonstein, M., Ehrlich, S. D., Overbeek, R., and Kyrpides, N. 2003. Genome sequence of Bacillus cereus and comparative analysis with Bacillus anthracis. Nature 423:87-91.

Jiang, M., Shao, W. L., Perego, M., and Hoch, J. A. 2000. Multiple histidine kinases regulate entry into stationary phase and sporulation in Bacillus subtilis. Mol. Microbiol. 38:535-542.

Jones, J. T., Haegeman, A., Danchin, E. G. J., Gaur, H. S., Helder, J., Jones, M. G. K., Kikuchi, T., Manzanilla-López, R., Palomares-Rius, J. E., Wesemael, W. M. L., and Perry, R. N. 2013. Top 10 plant-parasitic nematodes in molecular plant pathology. Mol. Plant Pathol. 14:946-961.

Joshua, G. W., Karlyshev, A. V., Smith, M. P., Isherwood, K. E., Titball, R. W., and Wren, B. W. 2003. A Caenorhabditis elegans model of Yersinia infection: Biofilm formation on a biotic surface. Microbiology 149:3221-3229.

Kearns, D. B., Chu, F., Branda, S. S., Kolter, R., and Losick, R. 2005. A master regulator for biofilm formation by Bacillus subtilis. Mol. Microbiol. 55:739-749.

Kerry, B. R. 2000. Rhizosphere interactions and the exploitation of microbial agents for the biological control of plant-parasitic nematodes. Annu. Rev. Phytopathol. 38:423-441.

Kotiranta, A., Lounatmaa, K., and Haapasalo, M. 2000. Epidemiology and pathogenesis of Bacillus cereus infections. Microbes Infect. 2:189-198.

Lemon, K. P., Earl, A. M., Vlamakis, H. C., Aguilar, C., and Kolter, R. 2008. Biofilm development with an emphasis on Bacillus subtilis. Curr. Top. Microbiol. Immunol. 322:1-16. 
Li, J., Zou, C. G., Xu, J. P., Ji, X. L., Niu, X. M., Yang, J. K., Huang, X. W., and Zhang, K. Q. 2015. Molecular mechanisms of nematodenematophagous microbe interactions: Basis for biological control of plant-parasitic nematodes. Annu. Rev. Phytopathol. 53:67-95.

López, D., Vlamakis, H., and Kolter, R. 2010. Biofilms. Cold Spring Harb. Perspect. Biol. 2:a000398.

Machanick, P., and Bailey, T. L. 2011. MEME-ChIP: Motif analysis of large DNA datasets. Bioinformatics 27:1696-1697.

Madec, E., Laszkiewicz, A., Iwanicki, A., Obuchowski, M., and Seror, S. 2002. Characterization of a membrane-linked Ser/Thr protein kinase in Bacillus subtilis, implicated in developmental processes. Mol. Microbiol. 46:571-586.

Manzanilla-López, R. H., Evans, K., and Bridge, J. 2004. Plant diseases caused by nematodes. Pages 637-716 in: Nematology: Advanced and Perspectives. Vol. 2. Nematode Management and Utilization. Z. X. Chen, S. Y. Chen, and D. W. Dickson, eds. CAB International, Wallingford, UK.

McLoon, A. L., Kolodkin-Gal, I., Rubinstein, S. M., Kolter, R., and Losick, R. 2011. Spatial regulation of histidine kinases governing biofilm formation in Bacillus subtilis. J. Bacteriol. 193:679-685.

Molle, V., Fujita, M., Jensen, S. T., Eichenberger, P., Gonzalez-Pastor, J. E., Liu, J. S., and Losick, R. 2003. The Spo0A regulon of Bacillus subtilis. Mol. Microbiol. 50:1683-1701.

Morris, C. E., and Monier, J. M. 2003. The ecological significance of biofilm formation by plant-associated bacteria. Annu. Rev. Phytopathol. 41:429-453.

Newman, J. A., and Lewis, R. J. 2013. Exploring the role of SlrR and SlrA in the SinR epigenetic switch. Commun. Integr. Biol. 6:e25658.

Newman, J. A., Rodrigues, C., and Lewis, R. J. 2013. Molecular basis of the activity of SinR protein, the master regulator of biofilm formation in Bacillus subtilis. J. Biol. Chem. 288:10766-10778.

Nielsen-LeRoux, C., Gaudriault, S., Ramarao, N., Lereclus, D., and Givaudan, A. 2012. How the insect pathogen bacteria Bacillus thuringiensis and Xenorhabdus/Photorhabdus occupy their hosts. Curr. Opin. Microbiol. 15:220-231.

Niu, Q., Huang, X., Zhang, L., Xu, J., Yang, D., Wei, K., Niu, X., An, Z., Bennett, J. W., Zou, C., Yang, J., and Zhang, K.-Q. 2010. A Trojan horse mechanism of bacterial pathogenesis against nematodes. Proc. Natl. Acad. Sci. U.S.A. 107:16631-16636.

O'Toole, G., Kaplan, H. B., and Kolter, R. 2000. Biofilm formation as microbial development. Annu. Rev. Microbiol. 54:49-79.

Peng, J. S., Tsai, W. C., and Chou, C. C. 2001. Surface characteristics of Bacillus cereus and its adhesion to stainless steel. Int. J. Food Microbiol. 65:105-111.

Pflughoeft, K. J., Sumby, P., and Koehler, T. M. 2011. Bacillus anthracis sin locus and regulation of secreted proteases. J. Bacteriol. 193:631-639.

Preston, J. F., Dickson, D. W., Maruniak, J. E., Nong, G., Brito, J. A., Schmidt, L. M., and Giblin-Davis, R. M. 2003. Pasteuria spp.: Systematics and phylogeny of these bacterial parasites of phytopathogenic nematodes. J. Nematol. 35:198-207.

Romero, D., Aguilar, C., Losick, R., and Kolter, R. 2010. Amyloid fibers provide structural integrity to Bacillus subtilis biofilms. Proc. Natl. Acad. Sci. U.S.A. 107:2230-2234.

Romero, D., Vlamakis, H., Losick, R., and Kolter, R. 2011. An accessory protein required for anchoring and assembly of amyloid fibres in B. subtilis biofilms. Mol. Microbiol. 80:1155-1168.

Ryu, J. H., and Beuchat, L. R. 2005. Biofilm formation and sporulation by Bacillus cereus on a stainless steel surface and subsequent resistance of vegetative cells and spores to chlorine, chlorine dioxide, and a peroxyacetic acid-based sanitizer. J. Food Prot. 68:2614-2622.

Schaeffer, P., Millet, J., and Aubert, J. P. 1965. Catabolic repression of bacterial sporulation. Proc. Natl. Acad. Sci. U.S.A. 54:704-711.
Shaheen, R., Svensson, B., Andersson, M. A., Christiansson, A., and Salkinoja-Salonen, M. 2010. Persistence strategies of Bacillus cereus spores isolated from dairy silo tanks. Food Microbiol. 27:347-355.

Shemesh, M., and Chai, Y. 2013. A combination of glycerol and manganese promotes biofilm formation in Bacillus subtilis via histidine kinase KinD signaling. J. Bacteriol. 195:2747-2754.

Shi, L.-B., Wang, Z.-H., Wu, H.-Y., and Liu, J. 2010. Influence of continuous tomato-cropping on second-stage juveniles of root-knot nematode and free-living nematodes from rhizosphere soil in plastic greenhouse. Acta Phytopathol. Sin. 40:81-89.

Sikora, R. A., and Fernandez, E. 2005. Nematode parasites of vegetables. Pages 319-392 in: Plant-Parasitic Nematodes in Subtropical and Tropical Agriculture, 2nd ed. M. Luc, R. A. Sikora, and J. Bridge, eds. CABI Publishing, Wallingford, UK.

Styer, K. L., Hopkins, G. W., Bartra, S. S., Plano, G. V., Frothingham, R., and Aballay, A. 2005. Yersinia pestis kills Caenorhabditis elegans by a biofilm-independent process that involves novel virulence factors. EMBO Rep. 6:992-997.

Tan, M. W., Mahajan-Miklos, S., and Ausubel, F. M. 1999. Killing of Caenorhabditis elegans by Pseudomonas aeruginosa used to model mammalian bacterial pathogenesis. Proc. Natl. Acad. Sci. U.S.A. 96:715-720.

Tian, B., Yang, J., and Zhang, K. Q. 2007. Bacteria used in the biological control of plant-parasitic nematodes: Populations, mechanisms of action, and future prospects. FEMS Microbiol. Ecol. 61:197-213.

Timmusk, S., Grantcharova, N., and Wagner, E. G. 2005. Paenibacillus polymyxa invades plant roots and forms biofilms. Appl. Environ. Microbiol. 71:7292-7300.

Trudgill, D. L., and Blok, V. C. 2001. Apomictic, polyphagous root-knot nematodes: Exceptionally successful and damaging biotrophic root pathogens. Annu. Rev. Phytopathol. 39:53-77.

Verhamme, D. T., Murray, E. J., and Stanley-Wall, N. R. 2009. DegU and Spo0A jointly control transcription of two loci required for complex colony development by Bacillus subtilis. J. Bacteriol. 191:100-108.

Vlamakis, H., Chai, Y., Beauregard, P., Losick, R., and Kolter, R. 2013. Sticking together: Building a biofilm the Bacillus subtilis way. Nat. Rev. Microbiol. 11:157-168.

Wang, Y., Fu, J., Zhu, Q., Zhu, L., Zheng, J., Liu, H., Peng, D., Ruan, L., and Sun, M. 2016. Complete genome sequence of Bacillus thuringiensis serovar alesti BGSC 4C1, a typical strain with toxicity to Lepidoptera insects. J. Biotechnol. 239:61-64.

Wei, L. H., Xue, Q. Y., Wei, B. Q., Wang, Y. M., Li, S. M., Chen, L. F., and Guo, J. H. 2010. Screening of antagonistic bacterial strains against Meloidogyne incognita using protease activity. Biocontrol Sci. Technol. 20:739-750.

Wijman, J. G., de Leeuw, P. P., Moezelaar, R., Zwietering, M. H., and Abee, T. 2007. Air-liquid interface biofilms of Bacillus cereus: Formation, sporulation, and dispersion. Appl. Environ. Microbiol. 73:1481-1488.

Xue, Q. Y., Chen, Y., Li, S. M., Chen, L. F., Ding, G. C., Guo, D. W., and Guo, J. H. 2009. Evaluation of the strains of Acinetobacter and Enterobacter as potential biocontrol agents against Ralstonia wilt of tomato. Biol. Control 48:252-258.

Yan, F., Yu, Y. Y., Wang, L. Y., Luo, Y. M., Guo, J. H., and Chai, Y. R. 2016. The comER gene plays an important role in biofilm formation and sporulation in both Bacillus subtilis and Bacillus cereus. Front. Microbiol. 7:1025.

Zasada, I. A., Halbrendt, J. M., Kokalis-Burelle, N., LaMondia, J., McKenry, M. V., and Noling, J. W. 2010. Managing nematodes without methyl bromide. Annu. Rev. Phytopathol. 48:311-328.

Zeriouh, H., de Vicente, A., Perez-Garcia, A., and Romero, D. 2014 Surfactin triggers biofilm formation of Bacillus subtilis in melon phylloplane and contributes to the biocontrol activity. Environ. Microbiol. 16:2196-2211. 